\title{
SERVICES AND PROGRAMMING PROVIDED BY POST-SECONDARY \\ INSTITUTIONS FOR INTERNATIONAL STUDENTS: EXPERIENCES OF SELECT \\ FEMALE STUDENTS FROM NIGERIA
}

by

Mofiyinfoluwa Badmos, BA, University of Ontario Institute of Technology, 2015

\author{
A Major Research Paper \\ presented to Ryerson University \\ in partial fulfillment of the requirements for the degree of \\ Master of Arts \\ in the Program of \\ Immigration and Settlement Studies
}

Toronto, Ontario, Canada, 2016

(C) Mofiyinfoluwa Badmos 2016 


\begin{abstract}
Author's Declaration
I hereby declare that I am the sole author of this Major Research Paper. This is a true copy of the MRP, including any required final revisions, as accepted by my examiners.

I authorize Ryerson University to lend this MRP to other institutions or individuals for the purpose of scholarly research.

I further authorize Ryerson University to reproduce this MRP by photocopying or by other means, in total or in part, at the request of other institutions or individuals for the purpose of scholarly research.

I understand that my MRP may be made electronically available to the public
\end{abstract}




\title{
SERVICES AND PROGRAMMING PROVIDED BY POST-SECONDARY INSTITUTIONS FOR INTERNATIONAL STUDENTS: EXPERIENCES OF SELECT FEMALE STUDENTS FROM NIGERIA
}

\author{
Mofiyinfoluwa Badmos \\ Master of Arts, 2016 \\ Immigration and Settlement Studies \\ Ryerson University
}

\begin{abstract}
The number of international students in Canada has been increasing over the years, as the Canadian government and educational institutions have begun to acknowledge their economic and cultural benefits (Alboim, 2011). This study explores the services currently provided by post-secondary institutions in the Greater Toronto Area to international students. More specifically, it is a gender-based analysis, exploring the specific needs (and if and how they are met) of female international students from Nigeria. Data were gathered from in-depth audiorecorded interviews with eight female international students from Nigeria and two international student advisors working in post-secondary institutions in the GTA. Analyzing the interviews showed that there are unique needs of international students from Nigeria and gender should be taken into account when considering their needs. The study utilizes post-colonial feminist theory and intersectionality as frameworks. It is hoped that this research will contribute to a greater understanding of the unique experiences and needs of some female international students from Nigeria.
\end{abstract}

Key words: International Students, services, female, Canada, Nigeria 


\section{Acknowledgements}

I would like to express my deepest gratitude to my amazing family and my ever supportive parents. I am very grateful to my parents for believing in and trusting me and providing the resources I needed to go through my academic career over the years. As an international student, I truly appreciate all their support.

I would also like to thank my supervisor, Dr. Patrizia Albanese for her dedication and kindness. I am so grateful for the drive, support and guidance she gave me by helping me explore and study a topic I am very passionate about and for the hours she put in into ensuring this was a solid MRP. I also want to thank Dr. Carmen Schifellite for his role as my second reader and his input, feedback and his support throughout the MRP writing process.

I also want to thank my amazing friend, Tiese, for her support throughout my year at grad school and through the MRP writing process and taking the time to read my MRP and help with the editing process.

I like to express my gratitude to the participants in this research who took time to share their experiences and open up to me. This research is for you and to make sure voices of international students are being heard.

Above all, I want to thank God for giving me the opportunity to gain this experience and the wisdom and strength to get through the process of writing this MRP. 


\section{Table of Contents}

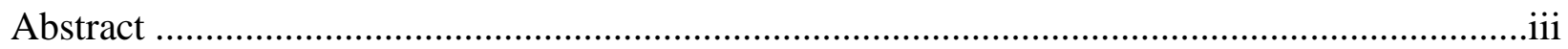

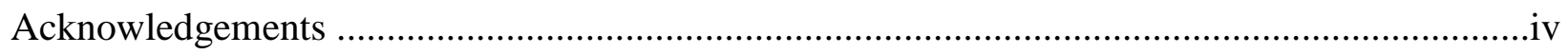

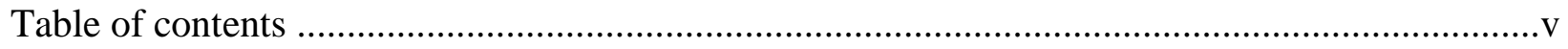

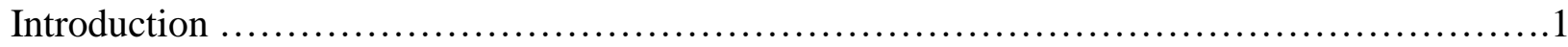

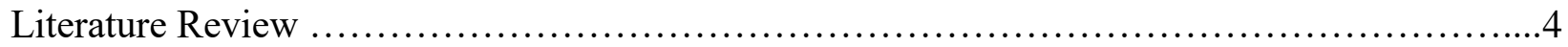

The rise and importance of international students for Canada .............................. 4

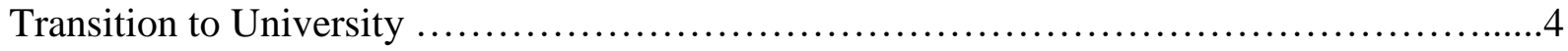

Often inadequate range of services available to international students ......................

Importance of recognizing international students as a Heterogeneous Group .................9

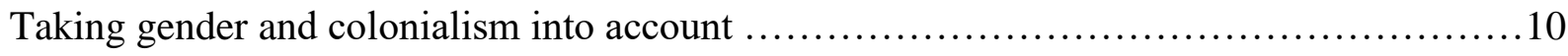

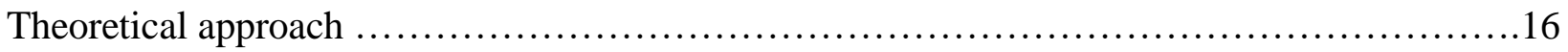

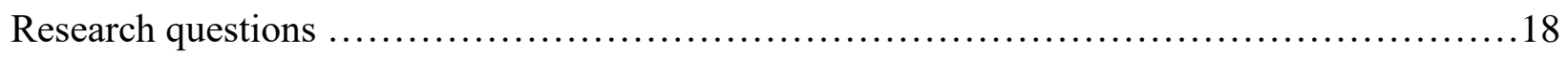

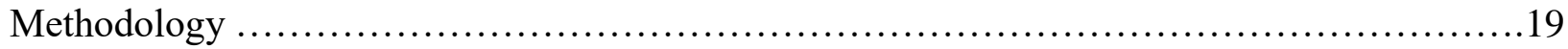

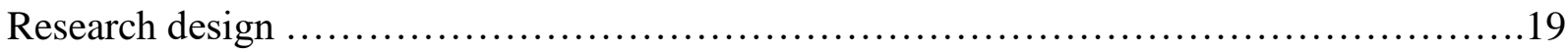

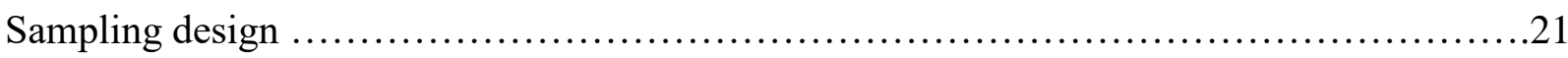

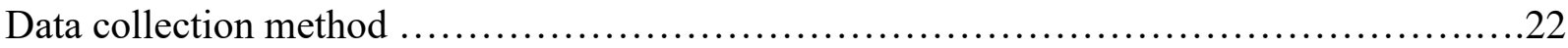

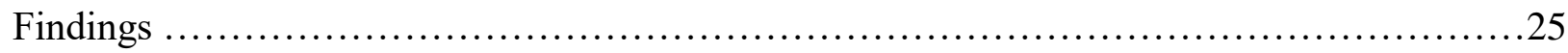

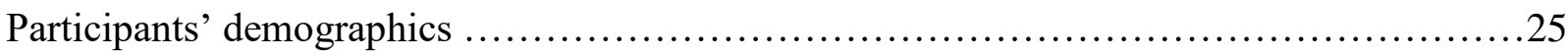

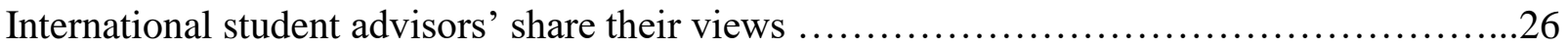

Services and programming available to international students ........................26

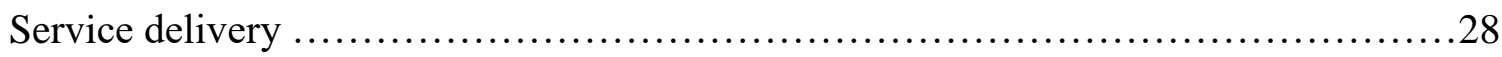

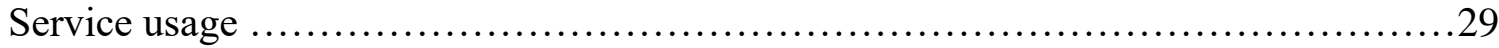

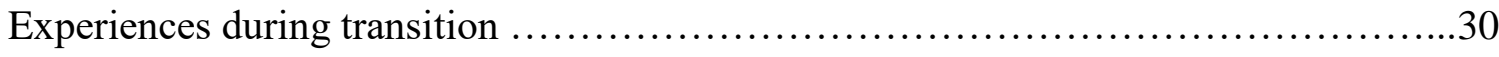

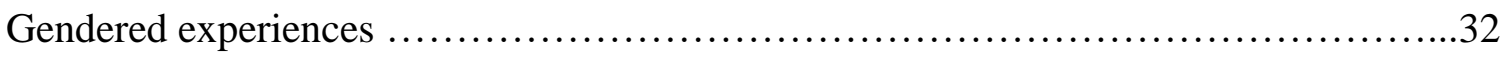

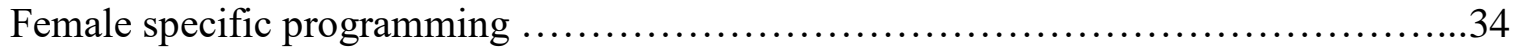

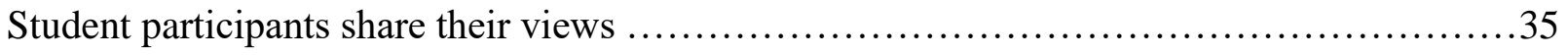

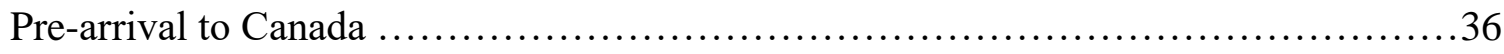

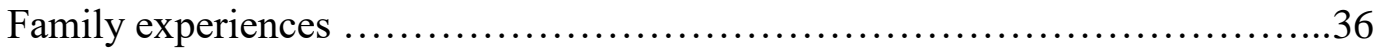




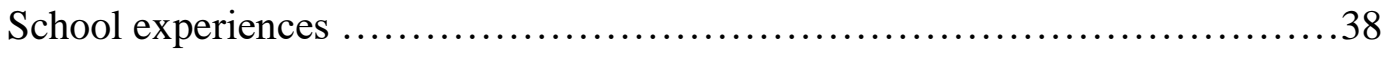

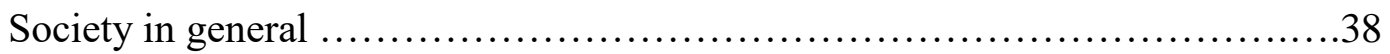

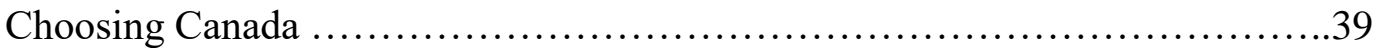

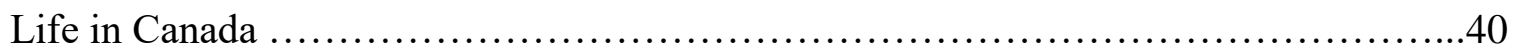

Academic expectations ................................................ 40

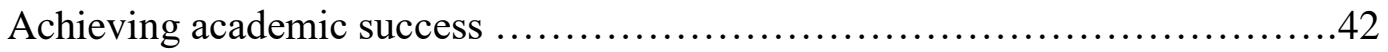

Experiences during transition .............................................43

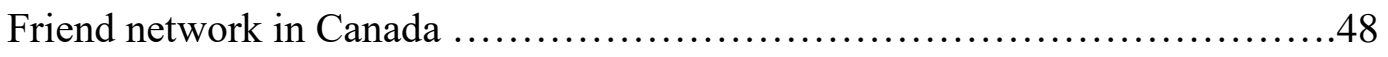

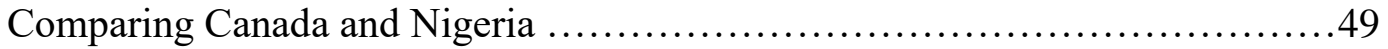

Comparing male and female international students' experience ..................51

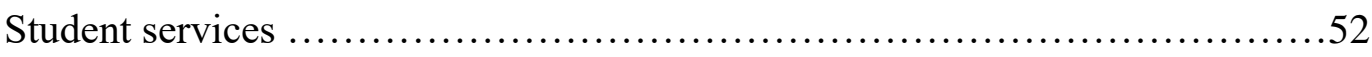

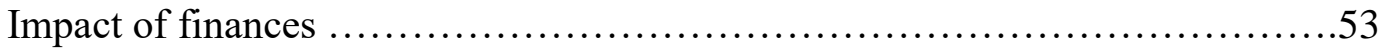

Investment in international students .......................................55

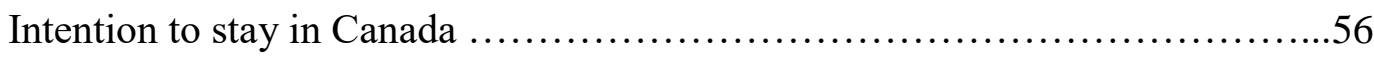

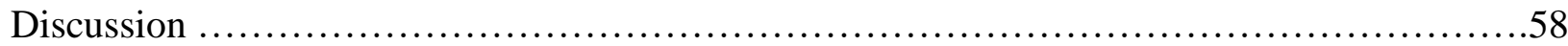

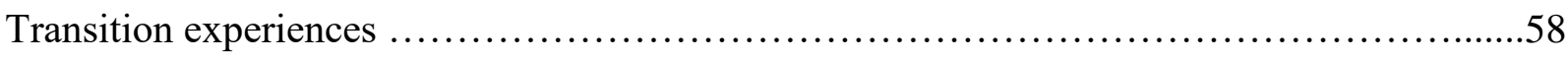

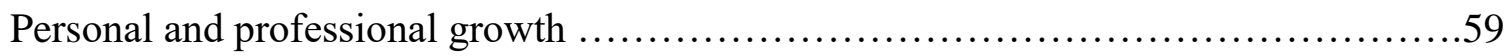

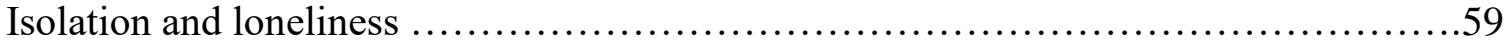

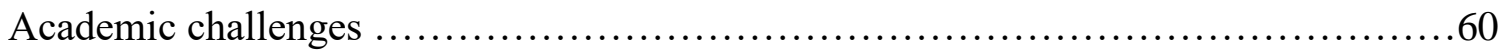

Female specific experiences and needs ........................................61

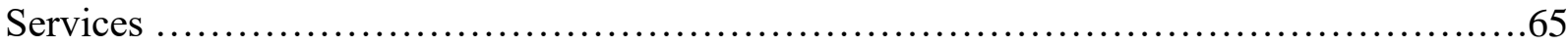

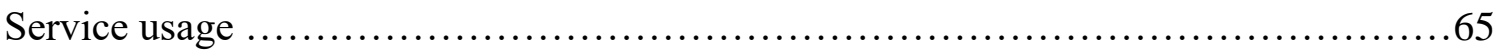

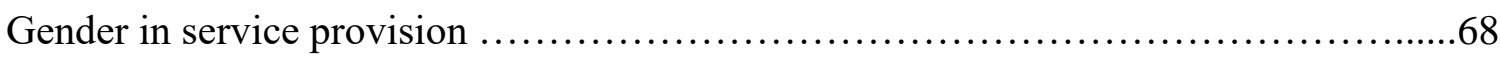

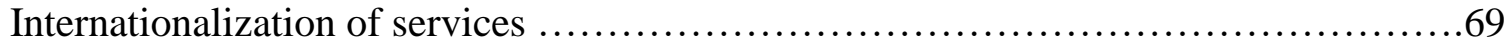

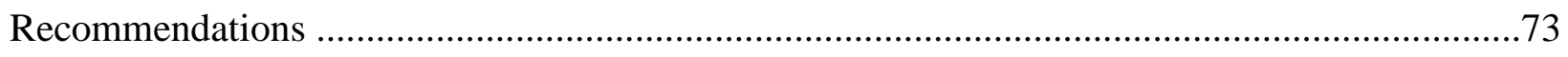

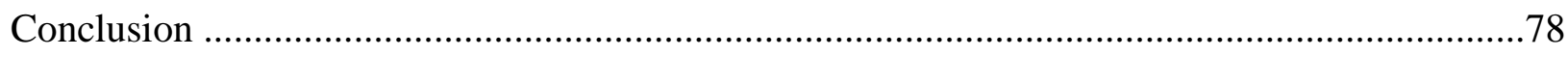

Appendix I. Ryerson Ethics Board Approval Letter ……………………………….....................8

Appendix II. Sample Recruitment Materials (Emails and Twitter) .............................................82 
Appendix III. Sample Interview Questions

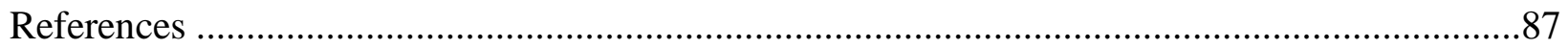




\section{Introduction}

Over the years, there has been a significant increase in the number of international students attending universities and colleges in Canada. According to the Canadian Bureau for International Education (CBIE) (2015), Canada is ranked as the world's $7^{\text {th }}$ most popular international student receiving country. As of 2014, there were 336,497 international students in Canada (CBIE, 2015). This represents an 83\% increase since 2008 (CBIE, 2015). Canadian postsecondary institutions attracting international students are making Canadian cities even more multicultural, which subsequently ties into Canada's immigration framework (Alboim, 2011). In 2014, the top three source countries are China, India, and South Korea, with 110,918 (33\%), 38,891 (12\%), and 19,358(6) international students respectively (CBIE, 2015). The number of International students from West-African countries have increased over the years. From 2002 to 2011 the number of international student from West-African countries increased from 641 students to 2123 (Facts and Figures, 2011). Those countries include Benin, Burkina Faso,

Gambia, Ghana, Guinea, Mali, Mauritania, Nigeria, Senegal, and Togo. Nigeria ranks $11^{\text {th }}$ in the list of countries sending international students to Canada. As of 2014, there were about 8,620 (3\%) Nigerian international students in Canada (CBIE, 2015). Nigeria has one of the fastest growing number of international students in Canada, registering a 25\% increase in 2014 (CBIE, 2015). This study focuses on International students from Nigeria because of the growing number of Nigerian international students in Canada.

In addition to enhancing multiculturalism, international students contribute to the Canadian economy (Gates-Gasse, 2010). The benefits international students bring to Canada have been acknowledged and have led to the 2014 collaboration between the Federal Government, the Department of Foreign Affairs, Trade and Development Canada (DFATD) and 
the new Global Markets Action Plan. Together they have committed to refocusing Canada's International Education Strategy in the hope of increasing the number of international students in Canada to 450,000 by 2022 (Govt. Canada, 2014).

After receiving admission from a Canadian institution, most international students enter Canada through a Study Permit and a Temporary Resident Visa (TRV), except for those arriving from Visa exempt countries; and Nigeria is not visa exempt ("Determine your eligibility", n.d.). To be eligible to study in Canada, students must prove financial stability to pay for tuition fees, living expenses, and return transportation ("Determine your eligibility", n.d.). They must be in good health and willing to complete a medical examination. Potential international students must also convince an immigration officer that they will leave Canada at the end of their authorized stay. In addition, they must be law-abiding citizens without criminal records ("Determine your eligibility", n.d.). International students must ensure their immigration documents remain valid while in Canada and they are responsible for renewing their immigration documents while still studying in Canada. After completion of their studies, international students have the option of remaining in Canada to work, with the option to eventually immigrate permanently through various streams ("Stay in Canada", n.d.). To work after graduation, students must apply for a work-permit under the Post-Graduation Work Permit Program (PGWPP) ("Stay in Canada", n.d.). A work permit issued under this program would be issued for the length of the student's program for up to a maximum of three years ("Stay in Canada", n.d.). This program allows for international students to gain Canadian work experience and helps them to qualify for permanent residence through Express Entry.

While not all students wish to remain in Canada following the completion of their studies, there are various streams in Canadian immigration policy available to international 
students that foster transitioning to permanent residence status. Despite the various avenues, there is a lack of services available to international students to aid in their economic and social transition to permanent residency in Canada (Roach, 2011). This is because service provision for international students is the responsibility of the post-secondary institutions they attend (Lowe, 2011). International students cannot access federally funded services that are provided to newcomer immigrants in Canada due to their temporary status. My study will explore services currently provided by post-secondary institutions to international students. I will specifically do this through a gendered lens, as I explore the unique experience and needs of, and the services available to and accessed by female international students from Nigeria who have settled in the Greater Toronto Area (GTA). The goal of my study is to understand the experiences and needs of female international students from Nigeria transitioning to Canadian society and postsecondary institutions and explore whether the services provided by post-secondary institutions in the GTA meet these needs. I will explore the unique challenges for female international students and how post-secondary institutions in the GTA address them. The analysis of data gathered through interviews with female international students from Nigeria and staff members of international student offices at post-secondary institutions in the GTA, aims to bring about a better understanding of the needs of female international students from Nigeria. 


\section{Literature Review}

This section discusses the common themes found in the literature. The themes explored

include: 1. the rise and importance of international students for Canada 2. transition to university; 3. the often inadequate range of services available to international students; 4 . the importance of recognizing international students as a heterogeneous group; and 5. the importance of taking gender and colonialism into account when it trying to understand West-African societies.

\section{The rise and importance of International Students for Canada}

International students are considered to be "ideal" immigrants or "designer" immigrants (Alboim, 2011). They have lived in Canada, have Canadian qualifications, speak at least one of the official languages, and they are culturally diverse. It is assumed that they are less likely to encounter major settlement and integration challenges than new immigrants usually do (Alboim, 2011). This conceptualization as "ideal" immigrants is reflected in immigration policies that provide various pathways to permanency for international students (Fama, 2011). In addition to their "ideal" immigrant status, international students benefit the Canadian economy even as temporary migrants (Alboim, 2011; Gates-Gasse, 2010). The revenue received from international students is greater than that received from exporting coniferous lumber or coal, as about $\$ 8$ billion is derived annually from international students' tuition and living expenses in Canada (CBIE, 2015; Gates-Gasse, 2010).

\section{Transition to university}

The first year of university is an important and complicated year for many students regardless of whether they are Canadian high school graduates, mature students, first-generation students, international students, or domestic students (Pidgeon \& Andres, 2005, Sinacore \& 
Lerner, 2013.) Although the transition to university overall tends to be a positive experience, some students nonetheless tend to face social, cultural and academic challenges when adjusting to their new environment (Pidgeon \&Andres, 2005). First year students tend to experience challenges surrounding academic adjustment, career planning, residence life, making friends and many others (Pidgeon \& Andres, 2005). New students have to adapt to the university learning environment. According to Pidgeon and Andres (2005), domestic students along with international students felt that large classrooms hindered their learning and socialization to university. Students mentioned that the ability to engage in classroom discussion or understand a lecture in a large classroom is difficult (Faid-Douglas, 2000; Pidgeon \& Andres, 2005). Time management was also found to be an issue for many students regardless of whether they were international or domestic students (Pidgeon \& Andres, 2005).

Living in residence was found to help students in finding social support or networks. Many students felt that living in student residences was important to meeting and establishing friends with other international and domestic students (Pidgeon \& Andres, 2005). However, living in residence was found to be a challenge because it could be an isolating experience for students who do not enjoy the residence culture, especially the social aspects of living in residence. Meeting friends was found to be a challenge for many students, both international and domestic (Pidgeon \& Andres, 2005). Some students found that socializing became easier by the second semester, if they lived in residence.

Adjusting to the physical environment is an important aspect of transitioning to university. Many students found that they had minor illness such as flu and headaches which could be attributed to adjusting to a new environment, unhealthy eating or living in residence where illness tends to circulate (Pidgeon \& Andres, 2005). Cultural diversity of institutions is 
appreciated and valued by both international and domestic students (Pidgeon \& Andres, 2005). Although cultural adjustment is a challenge faced primarily by international students, minority domestic students or immigrant $\left(1^{\text {st }}\right.$ generation or $2^{\text {nd }}$ generation $)$ students also experience these challenges (Sinacore \& Lerner, 2013). In addition to navigating a new language while

transitioning to Canadian society and education system, immigrant students become more aware of their racial, ethnic, religious and culturally minority status once they arrive in Canada and some report facing discrimination (Sinacore \& Lerner, 2013). Adjusting to school becomes more complicated when they face discrimination or prejudice (Sinacore \& Lerner, 2013). Not surprising, students who study in their home province have different experiences than those who move out-of-province to study. Out-of-province students are adjusting to living in a new province, negotiating the culture of the province and developing new social relationships (Pidgeon \& Andres, 2005).

\section{International students' experiences}

International students experience challenges of not only adjusting to the shift in learning but also to the new teaching styles in Canada and their roles as students in a Canadian classroom (Pidgeon \& Andres, 2005). Some of these challenges include a reluctance to participate fully in class discussions and ask for clarification of issues or assignments (Pidgeon \& Andres, 2005). These challenges come from students who lack confidence due to their perceived limitations in their English proficiency or the difference in relationship between students and professors when compared to their home countries (Pidgeon \& Andres, 2005). The authors discuss that faculty need to be more internationalized in their teaching styles and class management techniques in order to meet the needs of international students (Pidgeon \& Andres, 2005). 
Although making friends was a challenge for both international and domestic students, international students were found to face greater difficulties making friends with domestic students. Pidgeon and Andres (2005) found that international students had different types of friends such as "hi-bye" friends, just classmates, residence acquaintances and many others but friend's from one's own cultural group tended to be closer than the others. English proficiency was discussed as a barrier to establishing cross-cultural friendships. In addition, developing friendships within one's cultural or ethnic group allowed for a common understanding, culturally and socially, which allows for the development of strong support networks to be formed, according to research by Pidgeon and Andres (2005).

The literature emphasizes that cultural adjustment is an issue for international students (Faid-Douglas, 2000; Pidgeon \& Andres, 2005; Regina, 2003). Adjusting to the Canadian culture in terms of social relationships was a challenge for international students. Some students felt they had experienced racism or were treated unjustly within the university or within their larger community (Pidgeon \& Andres, 2005). Some students also face challenges adapting to the food in their new community.

\section{Often inadequate range of services available to International Students}

Although the international student population is increasing in Canada, there is little investment in settlement and transition support for international students (Lowe, 2011). Lowe (2011) discusses that there are gaps in specialized services for international students when they transition from student to worker to immigrant. Research shows that the cost and burden of transition and settlement is on the students themselves and the institutions they attend (GatesGasse, 2010). As a result, the primary source of support is from the educational institutions that accept them, but comprehensive settlement support is beyond the mandate of most institutions 
(Chira, 2011). In addition, many institutions lack the funding to provide specialized services for international students (Gates-Gasse, 2010). As a result, services for international students vary by institution. For instance, smaller institutions might not have the resources to provide services compared to larger institutions (Gates-Gasse, 2010). A significant point raised by Gates-Gasse (2010) is the problem that international students are only seen, and treated, as sources of revenue. Less attention is paid to the specific resources they may need once they arrive at a postsecondary institution.

The benefits discussed earlier highlight how important international students are to the Canadian economy but seeing them solely as a revenue stream, dehumanizes them and affects how they are perceived by service providers, which in turn can affect the transition services they receive (Gates-Gasse, 2010). In Nova Scotia, Gates-Gasse (2010) found that international students spent $\$ 3.80$ for every dollar that the provincial government spent on them. That study found that universities spent less on international students than on domestic students (GatesGasse, 2010).

Kamara and Gambold (2011) found that international students are disappointed with the level of support they receive from their institutions. Likewise, Lowe (2011) has argued that the lack of adequate settlement and transition support for international students might lead to students choosing to immigrate to a different country. The author noted that this would be a loss for Canadian post-secondary institutions and Canadian society as a whole (Lowe, 2011). The lack of services for international students, particularly while they transition from their temporary status to permanent immigration status, is well documented in the literature. However, research is lacking on the impact of the lack of services on international students' general well-being and 
on how they experience the transition to living in Canada and to starting at post-secondary institutions.

\section{Importance of recognizing international students as a Heterogeneous Group}

Bonazzo and Wong (2007) have critically assessed the literature on international students and have found that studies typically lump all international students into one category. Often studies ignore in-group differences, resulting in difficulties in accurately addressing their unique challenges and needs (Bonazzo \& Wong, 2007; Faid-Douglas, 2000). Culture is one of the most obvious differences that needs to be taken into account when studying international students. Gender is another category to consider while exploring international students' experiences. Bonazzo and Wong (2007) mention that gender role differences might bring about different experiences between male and female international students. Faid-Douglas (2000) expanded on this further by stating that gender is a very important variable to study as compared to focusing only on the idea of being "foreign" or being culturally different.

Research by Bonazzo and Wong (2007) found that female international students in their study reported experiencing discrimination and prejudice on university campuses both by students and faculty. They discuss that these experiences stem from perceived cultural differences; for instance, being made fun of because of language barrier, or having short hair (which is common among many Japanese women). On the other hand, Kamara and Gambold (2011) noted that international students tended to feel more comfortable on campus, as compared to off-campus. They explained that because 57 percent of international students coming to Canada are visible minorities, particular attention needs to be paid to the experiences and effects of racism on this body of students (Kamara and Gambold, 2011). Research by Park (2010) complemented this finding, as the author found that the intersection between race and culture, 
increased the probability of female Asian students being attacked in Vancouver. In a similar vein, Bonazzo and Wong (2007) noted that international students face greater psychological distress than their domestic counterparts.

Academic success is found to be the number one priority for international students; however, international students face difficulties adapting to the change in academic requirements (Faid-Douglas, 2000). Faid-Douglas (2000) found that female international students face more difficulties adjusting to university as compared to male international students. Hwang, Bennett, and Beauchemin (2014) point out that adjustment factors like cultural and language difference, and adapting to a new environment increase the chances of international students experiencing mental health challenges compared to domestic students. Other studies show that international students encounter loneliness and isolation during their transition to Canada (Faid-Douglas, 2000; Popadiuk, 2008). They typically leave their social support network back home when they begin studying abroad (Popadiuk, 2008). Faid-Douglas (2000) discusses the fact that they face difficulties when making Canadian friends. Likewise, Popadiuk (2008) argues that isolation and loneliness are the two significant predictors of how well international students will cope in their new surroundings. Adding gender to the mix makes matters even more complex.

\section{Importance of taking gender and colonialism into account}

As mentioned earlier, understanding a student's cultural background and the impact of culture is very important in understanding the specific needs of international students. In addition, it is important to understand the experiences of students from the context of their home countries. It is very important to note that prior to amalgamation in 1914, what is now Nigeria was comprised of independent and self-governed states, kingdoms, and nations (Nwanesi, 2006). There are a variety of traditions, customs, and languages, with about 250 ethnic groups. In pre- 
colonial Nigeria, women contributed to the well-being of their family, buying and selling, and they were involved in production and distribution of goods. (Nwanesi, 2006). Nwanesi (2006) emphasizes that women were active participants and dominated the local economy prior to colonization. However, women held a subordinate position in Nigeria and were still dependent and subordinate to their husbands because being a wife was perceived to be the most important status (Abdulraheem, 2011; Nwanesi, 2006). This was not peculiar to Nigeria alone but the world at large (Abdulraheem, 2011). A formal education system was non-existent prior to colonialism, and was vocational and classified into gender suitable occupations (Abdulraheem, 2011). However, this was not intended to be discriminatory but designed to provide women with the skills to run the family; and through this system, men and women had the option to choose whatever occupation they liked (Abdulraheem, 2011; Nwanesi, 2011). The colonial economy was focused on export and this disrupted the occupations of Nigerian women (Nwanesi, 2011). The colonial presence placed women at a great disadvantage, which is still reflected in Nigeria today (Nwanesi, 2011). Upon arrival, the British established Western schools in Nigeria, which were introduced primarily to male children. Eventually some restrictions on women were lifted but education was still limited to domestic education such as cooking, house keeping etc. The colonial intention was to discipline them in accordance with the African culture and traditions pre-colonialism (Abdulraheem, 2011). Although this focuses primarily on education, the arrival of the British in many African cultures, including Nigeria, brought about many changes, mainly in education, politics, social activities, and economics (Abdulraheem, 2011). Ultimately, due to the simple fact of being 'female', women in African societies have been exposed to varying forms of discrimination since colonialism (Allanana, 2013). 
Allanana (2013) emphasizes that in Nigeria "womanhood is reduced to a mere infidel and a second-class citizen, hence, there is the commonality of general belief system that the best place for women is the kitchen" (p. 115). The patriarchal nature of Nigerian society enables men to dominate women. In Nigeria, women are discriminated against from acquiring formal education, face disadvantages in employment, and lack health and civil rights (Allanana, 2013; Aja-Okorie, 2013). Although international human rights law states that girls should have an equal right to education, the implementation of this right is lacking in Nigeria (Aja-Okorie, 2013). From 2008 to 2012, the youth literacy rate of young women in Nigeria aged 15-24 was 58 percent compared to 77 percent of young men in the same age group ("At a glance", n.d.). The author discussed that the higher literacy rate of young men can be attributed to religion, culture, economy, early marriage and general unfavourable attitude expressed towards educating women and girls (Oniye, 2013). In Nigerian society, the education of male children is prioritized because they are perceived to be more valuable once educated (Aja-Okorie, 2013). In addition, some families believe that investing in girls' education is investing in the family she will marry into (Allanana, 2013). This mentality is prevalent in higher education, where the costs are higher and consequently, it is considered as less necessary for women whose main roles will eventually be home keeping and child bearing (Allanana, 2013). This perception is rooted in the colonial system of education, where the meeting the manpower need of the colonial government alienated women from educational and economic opportunities (Allanana, 2013). During the colonial era, work was allocated for men and home-keeping for women. These attitudes manifest when the parents lack resources to enroll all children in school (Allanana, 2013). The result of this history is that there is a lower post-secondary school enrolment rate for girls compared to boys (Oniye, 2013). According to Oniye (2013), relative wealth is seen to have an effect on equity, as most 
girls leave school due to their families' inability to pay the costs associated with education. Research by Oniye (2013) also found that 70 percent of Nigerian women aged 35 years and above are illiterate. This high level of illiteracy can be attributed to the patriarchal nature in some African traditions and culture that reduces women to kitchen manageresses and baby producers (Oniye, 2013). Oniye (2013) discusses that women are typically responsible for traditional family roles which include home maintenance, feeding the family, and custody of children. In African societies, women are socialized to believe that certain professions and interests are exclusive to men (Oniye, 2013). Socialization in African societies has lead some women to accept negative self-fulfilling prophecies, and stereotypes, and accept the stigma that they are the inferior sex (Aja-Okorie, 2013; Oniye, 2013).

This feeling and impact of a sense of inferiority among women in some African societies is not limited to education, but is manifested in other aspects of life as well, such as in their experiences at home and in the incidence of violence against women. Around the world, women are beaten, punished, raped and even murdered (Esere, Idowu, \& Omotosho, 2009). In some societies, girls and young women are forced into early marriages by parents and relatives. In many West-African societies, violence and abuse is prevalent, tolerated and frequently excused because it is culturally acceptable for women to be assigned an inferior role, and are seen as subordinate to men (Aihie, 2009; Esere et al., 2009). Gender based violence is prevalent because discriminatory laws condone and legalise certain forms of violence against women (Esere et al., 2009). West-African societies exhibit dismissive attitudes within the police and other parts of the justice system, highlighting states' failures to protect women's rights. Reports show that 60 percent of women who experience domestic violence and shared the information with family members were told to endure the circumstances (Aihie, 2009). 
Aihie (2009) sheds light on research that shows there are high levels of under-reporting and lack of domestic violence documentation due to cultural factors. The author discovered that many of the women in West-African societies did not know if they had experienced abuse or not. This is because most abusive behaviour is considered 'normal' within the culture. Violent acts are considered 'normal' or 'acceptable' in West-African cultures due to the patriarchal nature of those societies in which women and young girls are seen as inferior (Oniye, 2013). Young and older women in West-African societies are said to be victimized twice: first by the violence that they experience at the hands of men, and second, by the failure of the state to protect them (Esere et al., 2009). The authors also shed light on the effects of violence against young women (Esere et al., 2009). They note that violence limits young women's personal growth, productivity, socioeconomic roles, and their physical and psychological health. They add that these effects can have lifelong consequences for the individuals who experience violence (Esere et al., 2009). They also highlighted that the lack of social structures to stop the practice of gender based violence could make young women believe that they are inferior to their male counterparts and that they deserve the abuse (Esere et al., 2009). Inevitably, this can negatively affect their perception of themselves as women and their perceptions of men as well. Research by Ilyasu, Abubakar, Aliyu, Galadanci, and Salihu (2011) focused on Gender Based Violence (GBV) among university students in Nigeria. They found there was a high prevalence of GBV: 95 percent of respondents had experienced one or more forms of GBV, with 22.2 percent of young females experiencing some sort of sexual abuse, 22.8 percent experiencing physical violence and 51 percent experiencing emotional and verbal abuse. (Ilyasu, Abubakar, Aliyu, Galadanci, and Salihu, 2011). They also found that a result of GBV, their experiences can lead to insecurity and thus might discourage them from enrolling in higher institutions. 
Clearly, all their research indicates that young women from the region who are interested in and able to pursue their studies abroad are not the norm; and it is important to explore how culture, patriarchy, and colonialism have affected their experiences in school, both at home and abroad. 


\section{Theoretical approach}

This paper is grounded in post-colonial feminist theory and an intersectionality framework. In this work, I argue that the experiences of Nigerian female international students will be better understood through exploring the intersection of race, culture, and gender as expressed through postcolonial feminist theory. The two approaches go hand-in-hand and contribute to a more complex and nuanced understanding of the experiences and needs of Nigerian female international students. While traditional feminist approaches have done a great deal to bring attention to and advance the position of women in society; postcolonial feminism has emerged as a critique of traditional Western feminist approaches that have often homogenized the experiences of women to achieve such advances (Mishra, 2013). Western feminism has been criticized as promoting a white discourse and a narrow range of women's needs, at the expense of women from colonized nations (Mishra, 2013). According to Schwarz and Ray (2005), postcolonial feminism is an exploration of the experiences of women in and with colonialism and neocolonialism, with a particular emphasis on understanding the intersection of gender, nation, class, and race, in the different contexts of women's lives, including their subjectivities, work, sexuality, and rights. Chandra Mohanty, a postcolonial feminist, is critical of traditional Western feminism's disregard for the unique experiences of women in postcolonial nations. She too has been critical of the categorizing of women into a homogenous group and not acknowledging differences based on race, class and other circumstances (Mohanty, 1988). Postcolonial feminists argue that women suffered 'double colonization' as they were first colonized subjects (along with men in their culture), and secondly, by being women in patriarchal societies (Mohanty, 1988; Tyagi, 2014). In this context, 
the fight against cultural imperialism from the West in the 1960s, led to women's issues being ignored and sacrificed (Tyagi, 2014).

Western feminism has often been critical of economic, social, and religious familial structures, but at the same time, in their critical analyses, have either ignored significant differences among women or have inadvertently treated "third world" women as 'Others' when compared to Western women (Tyagi, 2014). For example, in some analyses, Western feminists have represented themselves as free-minded and in control of their own lives, while women from the "third world" have been represented as family-oriented, illiterate and domestic (Tyagi, 2014). Mohanty's postcolonial feminist theory deconstructs the "first world versus third world woman" and "men as oppressors versus women as victims" binaries (Mohanty, 1988). The main objective of postcolonial feminists is to make differences such as race, class, and circumstances, in the lives of women visible and recognizable in Western feminism and in non-oppressive ways (Mishra, 2013). 


\section{Research questions}

In this research paper, my primary focus is on the question: do the services and programming provided by post-secondary institutions in the GTA to international students aid in their transition and settlement in Canada and meet the gender specific needs of female international students from Nigeria? Sub-questions to be explored are:

1. What are the needs of international students coming from Nigeria?

2. Does the patriarchal nature of West African societies play a role in the needs of female international students from the region?

3. What are those gender specific needs?

4. How are the needs of international students addressed by post-secondary institutions in the GTA?

5. Does young women's access to and usage of services play a role in their decisions surrounding their desire to pursue permanent residence in Canada? 


\section{Methodology}

\section{Research design}

This study utilized qualitative research methods to better understand the needs of female international students from Nigeria and to identify common themes that describe their experiences before and after migration. Quantitative research has examined the lack of adequate transitional and settlement services for international students (Lowe, 2011; Cox, 2014). Research by Lowe (2011) found that providing settlement support is beyond the mandate of most postsecondary institutions. Therefore, researchers discuss the importance of the federal government providing services for international students (Lowe, 2011; Cox, 2014). However, the study of the of female international students, especially those coming from Nigeria is lacking. Qualitative research allows female students themselves to fill this gap by identifying and explaining what their transitional needs are, based on their lived experiences. According to Creswell (2013), the focus in qualitative research is on the process of research that "flows from philosophical assumptions, to interpretive lens and on to the procedures involved in studying social or human problems" (p.44). He added that qualitative research included the participants' voices, reflection from the researcher, interpretation and description of the problem, and provides a contribution to the literature which might bring about a call for change (Creswell, 2013). In addition, qualitative research involved various forms of data collection, which include, interviews, observations, document analysis and many others. The researcher then makes sense of the data collected across a range of sources and organizes them within the research (Creswell, 2013). These characteristics fit with the intention of this study to articulate gender specific needs of international students from Nigeria. 
Case study as a qualitative approach is the most appropriate method in this study. Case study refers to studying a case or cases within contemporary settings (Creswell, 2013). In case studies, the researcher studies the case or cases through in-depth and detailed data collection methods (Creswell, 2013). The first step in case-study research is identifying a specific case. According to Creswell (2013), it is essential to define a case that can be bounded or described within parameters such as time or place. The case studied are female international students from Nigeria who are enrolled in post-secondary institutions in the GTA. Case study is used when the focus of research is to understand human interpretations and their meanings (Oliver, 2004). It can provide understanding about the needs of female international students through their understandings of their experiences both at home and once in Canada, from their point of view. In case studies, it is important to be aware of the challenges with generalizability, this is because the contexts of cases differ (Creswell, 2013; Oliver, 2004). Case study findings cannot apply to whole populations but they can be transferred to other situations or can be used to explain other situations or experiences (Oliver, 2004). This is important in this research because findings specifically related to Nigerian female students in the GTA cannot be applied to the general female international student population. However, findings can shed light on the importance of gender in services and programming for international students and can prompt future research.

In order to fully understand a particular set of experiences or issues, it is important to approach the research very carefully, with an awareness of potential bias. This involves using a process called "bracketing" (Creswell, 2013). This is especially important in this study because I the researcher, am a member of the community in this research. I am a female international student from Nigeria. Bracketing allows for the researcher to focus on the experiences of the participants in the study. This process allows the researcher to describe experiences based on the 
results from their participants and not on what they know or assume they know (Faid-Douglas, 2000). Nonetheless, ultimately the process of bracketing does not exclude the researcher completely from the study but it allows the researcher to be self-aware of past knowledge and biases (Creswell, 2013).

\section{Sampling design}

The sampling design to be used for this study is purposeful sampling. Purposeful sampling as defined by Yin (2011) is selecting participants based on their anticipated richness and relevance of information in relation to the research questions. This is based on the significance of participants embodying specific criteria (Faid-Douglas, 2000). In addition to purposeful sampling, snowball sampling was utilized. Snowball sampling is identifying participants from current participants who know people who are information rich and who will benefit the study (Creswell, 2013). Interviews in this study have been carried out on two different demographics: (1) Female international students from Nigeria studying in GTA; and (2) International Student Advisors (ISA) as key informants. Key informants will be utilized in this study to understand the perception of the needs of female international students and identify any gaps in the services from the perspective of advisors providing assistance and support to this population. This method was utilized in a study by Roach (2011), and was beneficial in this study as well. The criteria for the student participants include: a) female international student, b) studying at a post-secondary institution in GTA, and c) from Nigeria. The criteria for the ISAs include those providing direct support to international students in the GTA. This is because ISAs providing direct support to international students would have a better understanding of their needs as they relate to transition to Canada and post-secondary institutions (Roach, 2011). 
The aim of sampling in qualitative research is to acquire in-depth information of an issue rather than generalizability, therefore, smaller sample sizes are typically used (Gentles, Charles, Ploeg, \& McKibbon, 2015). In case study, estimated sample size by researchers is from 4-10 participants (Creswell, 2013; Gentles et al., 2015). The design of this research is focused on a total sample size of 10 participants; eight student participants and two key informant participants. The focus is on the importance of selecting an adequate sample size that allows for in-depth information to be obtained and is not too small to bring about difficulties in reaching saturation (Onwuegbuzie \& Leech, 2007). Before beginning this research, I sought approval from Ryerson's Research Ethics Board (See Appendix I). Following their approval, I began data collection.

\section{Data collection method}

Data collection in case study typically draws on multiple sources of information (Creswell, 2013). These include: interviews, observations, audiovisual materials, and document analysis. This study utilized qualitative interviews with students and key informants. This began with recruitment of participants, followed by interviewing. The criteria for participant selection was ensuring they fit into the demographic being studied and be willing to share their experiences. The demographic being female, international student, studying at a post-secondary institution in the GTA, from Nigeria, and between the ages of 18-30. These criteria will be used in the process of recruiting and selecting participants. Recruitment was carried out differently for the students and the key informants. An email explaining the research study was sent out to various student union or student association groups serving African students (such as African Student Associations or Nigerian Student Associations) at post-secondary institutions in the GTA (See Appendix II). These emails included the contact information of the principal 
investigator which allowed interested students that fit the criteria to contact the principal investigator. Also, the email explained that participants would answer semi-structured interview questions that will be audio-recorded (if they agreed) that would be about 70 minutes long, and the voluntary nature of the research. In addition to emails, twitter was utilized to recruit participants, as social media can be an effective source of attracting student participants (See Appendix II). On the other hand, web searches of ISAs at post-secondary institutions in Toronto were made in order to identify potential key informants. The international student advisors identified were contacted via email soliciting participation. The emails also contained the information described above. Upon agreement to participate in the study by the students and ISAs, interviews were scheduled at a mutually agreed time and place, where privacy could be protected. Interviews were conducted at the institutions of the primary researcher in a private room and the institutions the ISAs work. The participants were provided with informed consent forms to emphasize the voluntary and confidential nature of participation. The interview questions are semi-structured open-ended questions (See Appendix III). Prior to the interviews, written consent was obtained, including consent to record the interview. Each interview lasted about $45-65$ minutes. Before the interviews began, student participants completed a form that asked for their demographic information stating their age, country of origin, length of stay in Canada, level of study, program of study, and post-secondary institution attending (though no institution names are included in this report or other dissemination). This allowed the researcher to have a better understanding of demographic information and provide more accurate reporting and analysis of the study.

The interview questions for the student participants were different from the questions asked of key informants (See Appendix III). The student participants were asked questions 
relating to their experiences as young women in their home countries, specifically relating to their education. They were asked to compare their experiences as female students in Canada to their home country. They were also asked their perception and usage of services provided by Canadian institutions. They were asked about the importance of their academic success. In addition, they were asked about their intention to permanently migrate to Canada and if services they received play a role in their decision to attempt to stay or leave Canada. I was especially interested in what they identify as reasons for their desire to return home. Lastly, they were asked what their needs as international students are, if their needs are being met and their views on how services may be improved. This format of the questions allowed participants to explain and discuss their transition needs, the reasons for these needs, and if their needs are being met. It also allowed participants to discuss issues that were not asked by the researchers.

The interviews were audio-taped upon agreement by the participants, the information was transcribed (one year after transcription, the original tapes will be destroyed). No participant or institutional names were used in the reporting of findings in order to protect privacy and maintain confidentiality. 


\section{Findings}

This section includes a description of the participants' demographics and discussions of the themes that emerged. Direct quotations from the interviews will be used to emphasize the themes and sub-themes that emerged. Participants quotations are presented verbatim from the transcripts, therefore, they include the exact grammar and word choices made by the participants. Identifying information such as names and universities have been replaced by pseudonyms or removed to protect the participants' identities. In addition to protecting confidentiality, pseudonyms were assigned to portray the participants' experiences more finely.

\section{Participants' demographics}

Ten semi-structured interviews were conducted with eight female international students and two ISAs. Every female international student's country of origin is Nigeria. Every participant completed high school education in Nigeria and are aged 18-25. All the participants' marital status is single and they had been in Canada for four to seven years. They all attended post-secondary institutions in the GTA. Seven out of eight participants attended a university in the GTA while one attended a college in the GTA. At the time of the interview, four participants were currently enrolled as students while four were recent graduates. All but one of the participants were enrolled as or just completed undergraduate level programs.

The two ISAs included in this study provide support to international students at Universities in the GTA. However, one university is a large university with thousands of international students while the other is a smaller university with less than 1000 international students. Participation for ISAs was restricted to those with experiences directly interacting with international students or providing programming for international students. 


\section{Services and programming available to international students}

During the summer before the international students attend orientation at their new institution, some institutions provide pre-orientation webinars that are intended to help students before they arrive at the institution. For example, the ISA at the large institution noted:

what we found was ... that you come to the university, you have all these questions and you're panicking and it's a new environment, so we wanted to start helping them before they arrive and sort of ease their transition into the campus

The webinars cover essential concerns like housing, eating, even information regarding driving. in Ontario. At the larger institution they also provide skype sessions, held by student staff, for incoming international students to assist them with concerns they might have before arriving in Canada. The smaller institution provides an Airport pick up program to assist international students arriving and travelling to the institution. The smaller institution also provides a New Arrival Support Program. This program pairs new international students with current student volunteers and these students meet with new international students upon arrival to assist them with items such as setting up a bank account, getting a phone plan, navigating the transit system, etc. The ISA at the smaller institution shared that the feedback they received from the students were very positive, stating:

100 percent that participated agreed or strongly agreed that they were happy they attended and felt less stressed and worried about being here and felt a little bit more confident in being able to navigate and being a little bit more independent.

Institutions also provide orientation programming for incoming international students. The larger institution hosts orientation programming in the fall, winter and summer with the fall orientation being the bigger one because the majority of students are admitted in the fall. In the larger institution, orientation programming grew from a two-day model to a six-day model to 
accommodate the growth in the number of new international students. In the smaller institution, orientation programming is a day long model. Orientation serves as a period to welcome new international students to university, to inform them about services the institution provides, and to make them feel acquainted with the international office. Information such as immigration needs, work eligibility, mental health and culture shock, academic expectations (at the smaller institutions), and connecting with peers. The ISA at the large institution stated that:

Our thing here at $\mathrm{X}$ international is that this is your home away from home type of scenario

The international office provides advising for students, information on health insurance and immigration, and they also provide referrals to other general departments in the institution. For example, the ISA at the large institution said:

I mean, we don't do academic advising but if you don't know where to go for academic advising, come and talk to us and we can direct you

The larger institution provides a global peer mentor program; it is a program where an older student is partnered with a new student as a mentor. The ISA at this institution explained:

So it could be anything from going to get a cup of coffee to showing them how to use the library and it's supposed to be very casual ... its a very important transition piece because they get to sort of go at their own place

The program is seen to benefit shy or more quiet individuals because they get the opportunity to interact with one individual that they might feel more comfortable with. Under the peer program, the international office runs events that target issues such as studying skills, rights in Canada, filing taxes and others. The ISA at the large institution mentioned that an important component of their mentorship is providing incoming students with opportunities to hear from current students. Institutions also host events during the periods the institution is closed for statutory holidays because they find that this could be really isolating and difficult for international 
students that don't have a home to go to while everyone else is away. The ISA at the large institution gave an example:

we run events for everyday of the closure so that gets them out and interacting with people ... its fun stuff like going to Niagara Falls in the winter time or go downtown and see the fireworks

\section{Service delivery}

Institutions as a whole have various departments that provide services to their entire student population, these include: financial services, registrar's office, academic advising, writing help and so on. Therefore, international offices do not provide these specific services to avoid the duplication of services. This was emphasized by the ISA at the large institution:

we have an office for everything, there's student financial services, registrar's office, X international and no body wants to step on the other's toes and so we tend not to overlap too much

The ISA at the large institution referred to this as a possible challenge because some students might not know where to go when they have specific issues and that can be difficult.

International students then tend to go to the international office to seek assistance and then get referred to the appropriate department. Overall, the goal is to ensure students do not leave unhappy, "so unfortunately sometimes that means we just have to refer you" (ISA, large institution). The ISA from the larger institution explained that some ISAs would go above and beyond to assist the student and make sure they are helped appropriately, but that is the exception rather than common practice. The ISA explained further:

I sort of know how to navigate the system so I'll help a little bit more than the typical person would help them ... that's an exception because not everybody has the kind of experience that I have had

An issue they face expressed by the ISA at the large institution is the shortage of staff across campus. This was noted by the ISA at the larger institution: 
I mean, our international student population is upwards of 6000 and we're just, in my team, we're like 5 people [laugh]. We have only one immigration specialist, so all over campus everybody is short of resources and that's a big problem so I would say in terms of where the issue comes in ... we try to do what we can

The services provided by the international student offices at both institutions are optional, the students are not required to attend any of the programming. Including the pre-arrival webinars hosted by the larger institution, NASP hosted by the smaller institution and Orientation programming. On this, the ISA from the large institution explained:

Its optional. We advertise it to them and just hope ... the participation is quite high ... I think the one they did on housing, my colleague was saying that they got about 75 questions, just questions.

\section{Service usage}

The underuse of services by international students is seen as a challenge raised by the international student advisors. The ISA from the large institution explained:

There are some people who come to $X$ and we never see them until they have a problem but it's usually a big problem ... those are the people we are trying to capture

They believe that international students might not use services based on two major reasons: the student's personality and on their fears of being perceived as needy. Some students feel independent and do not feel they need to use the support provided by services, therefore, they do not seek them out. The ISA from the large institution explained further:

Some students are just not built to participate and actively do things and so they just come and focus on their studies ... people who are more reserved and shy tend to not interact as much, those people are just afraid to seek the service because they don't want to feel like they're asking a dumb question

The lack of usage of services is not a problem unique only to international students, but it does seem somewhat more common among international students. 
International students not attending orientation might also be a reason why they are not aware of the services. For example, the ISA from the smaller institution said:

Don't have a lot of international students come to the orientation ... maybe the value isn't placed on what an orientation can do, maybe there's a misconception that it's all fun, maybe they think it's really boring or they don't need it.

Student retention is an important mandate for institutions. The goal is for students to remain in

their institutions. ISAs believe that services students receive might play a role in their decision to stay in Canada. For example, the ISA at the larger institution said:

Now that we have somebody who can advise on permanent residency ... it shows students ways in which they can stay in Canada and how, what the process is. They are more informed ... another thing and this really has nothing to do with the universities but more to do with immigration Canada, is they changed the length of time for the postgraduate work permit ... up to 3 years.

Similarly, the ISA at the smaller institution said:

Yes, orientation and transitional services. The more quickly you can adjust to a new environment, the more positive your experience, the more likely you are to stay. The idea is programming would retain them in school, whether they decide to stay in Canada is different ... the better experience, the more likely you are to stay and your experience can come down to your institutional experience.

In addition, the change in immigration regulations might encourage students to remain in Canada longer and help with their eligibility to work.

\section{Experiences during transition}

The ISA from the larger institution noted that students from African countries tend to face challenges with academics, and also specifically making the distinction between a CV and a resume, with academic dishonesty and understanding plagiarism. There was also reference to transitioning to the food in Canada after being used to food from your home country. Students from African backgrounds were also identified as possibly facing challenges in transitioning with 
regards to everyday life issues that are not challenges back home, such as, accents, housing, hair etc. The ISA from the large institution explained this further:

There is still some ignorance amongst some people but because they don't know, I don't blame them ... so dealing with that kind of transition, where you have to explain everything about yourself, it's like "oh, why do you braid your hair" or "why do you speak English so well" or "what kind of houses do you live in in Africa"

Although the ISA from the smaller institution interacts with student from this population, this

ISA could not identify what specific concern students from that region would experience. This

ISA said:

They haven't shared any experiences or issues that they're having. When you brought it up, it made me think about my part, perhaps I have to initiate a conversation like that more

Both ISAs stated that these are concerns that students do not think about when they are deciding to come to school in Canada. Their focus is on the academics but they also have to transition into the Canadian society. The ISA at the larger institution explained:

So these are things you might not necessarily be thinking of academically like when you come, you're like "I'm just going to X to study economics" you're not thinking about all those other things that come with the package and I feel like that's where a lot of the African students are maybe struggling

The ISA from the larger institution also discussed that expectations from family might have an

effect on the students and affect their academic performance and well being. This ISA said:

So things like that inadvertently affect you because then you come here and you're like "I must get all A's", "I must perform really well because so many people sacrificed to get me here" and those things end up affecting, or maybe making them not perform well academically ... they have a mental breakdown just because of something like that ... its all these strange things that you're not necessarily thinking of.

Both ISAs reported that that expectation is relatively the same for male and female international students. However, the ISA from the larger institution noticed that when parents accompanied 
students at orientation, they were parents of female international students. This ISA discussed

further:

We did have quite a number of parents and they tended to be for the female students and I don't know if that's more of like a safety thing or the parents are more worried that their girls are not going to adjust as well as the boys or boys have always been known to take care of themselves.

This ISA also made mention of the fact that students from African countries transition slowly to adopting the concept of extra curricular participation outside of academics. It was explained further:

I have seen a few students from Africa, they sort of sit in the background just observing because they're probably like ... "why is this emphasis on me participating in a student club" ... so I think those are some of the indirect things that ultimately impact academic life

\section{Gendered experiences}

Based on both ISAs interviewed, the response to gender specific issues varied. To start, the ISA from the larger institution said:

I don't know ... I guess because I never look at international students that way [laugh] ... I guess I've never thought about what would be specific to females

The ISA from the larger institution mentioned that cultural differences plays a bigger role, compared to gender differences. This ISA explained that:

Most people coming as international students are coming from a non-western ... the differences between men and women is distinct ... that sort of restriction that you would have back home is very different from the restrictions or non restrictions that you come here as an international student

The ISA added:

I think these days, they're all co-ed, I don't think there was ever a distinction between having women's only or men's only ... but then you come here and you're mixed with all the guys and you're like "okay what's going on"

On the other hand, the ISA at the smaller institution made mention of the fact that international female students might face the same gender specific challenges as domestic female students: 
Some of the challenges are cultural and culture isn't restrictive if you were born in Canada or not.

The smaller institution ISA found that there is a lack of sexual health education for female international students because they come from contexts where it is not discussed as much, and as a result, they encounter difficulties when they arrive in Canada.

The ISA at the larger institution mentioned that they do not consider gender when planning programming for international students for different reasons. The ISA provided further explanation:

So I'll tell you from a planning perspective. When I'm planning programs and services, I'm not thinking I want programming specifically for women or men, I'm just thinking international students in general and I guess that's because we sort of classify that all international students are going to have the same type of issues or concerns. Nobody is thinking that the women might have different questions from the men ... we've never thought of it, I guess

On the other hand, the ISA at the smaller institution mentioned gender specific programming is something they are considering. This would include programming to address cultural norms around dating, education around Sexually Transmitted Infections, contraception, female student interactions with male population and the expectations of working with groups that are males, especially with cultures where is it not the norm at the moment. They do not provide gender specific programming because they are a relatively new university and still developing. The ISA at the smaller institution explained:

We spent the last decade growing and figuring our student population and demographic. We've done work figuring out what the needs and gaps are ... some new roles have been created for inclusivity and that does include discussions about gender and gender specific programming and that's definitely in the horizon and we can expect it in the next couple of years. 
The ISA for the larger institution also made reference to the shortage of staff as a reason why they cannot plan programming specifically for female international students. On the other hand, the ISA referred to treating every student equally and not looking at gender. The ISA said:

Nowadays, I think like even the idea of gender is such a touchy subject that some people don't want to be referred to as either male or female they just want to be people ... like I said until you asked me that question earlier on, I hadn't even though "oh yeah what problems might international female students face versus males"

The ISA at the larger institution believes that based on her experience, female students might not face anything different than male students. The ISA added that there are difficulties differentiating between programming for undergraduate and graduate students that "I don't know if I would ever want to go to the gender side".

\section{Female specific programming}

Both ISAs noted that if not restricted by funding, they would incorporate gender specific programming. The ISA from the larger institution also cautioned against excluding male students at the same time,

I would have a lot of categories and gender is definitely one of those that I would sort of have programming specific to women. It's even things like safety, like taking care of yourself, how do you protect yourself ... I would be careful not to sort of exclude the males [laugh].

The ISA added:

We really don't look at gender specific and I would say because we are trying to be all inclusive ... we try to balance it out just because we don't want anybody to feel like they're not being included.

While on the other hand, the ISA from the smaller institution believes there should female specific programming and it is something that has been discussed. The ISA explained:

Coming from different nations or cultures, it's completely different if you're a male in that culture or you're a female. You have a completely different sub culture and so to assume women coming from one country and their needs are the same as men coming 
from one country ... same thing we're trying to do my creating opportunities for our international students to talk to one another. Here's another subculture within that that has unique needs.

The ISA added:

Though it might not be able to dissect based on everything for everybody, I think it's a pretty obvious one around gender.

ISAs discuss that some students might not feel they need support until it is pointed out to them that they need it. ISAs agree that female-specific programming would allow female students to open up and feel more comfortable and confident in their environment. The ISA at the large institution explained the importance of this:

They're just as important as any other needs and there's no need for sort of like a shame around it ... or to hold back because you're thinking "well this isn't relevant to anybody".

International students face various challenges during transition which can affect their mental health. Addressing mental health is an important mandate for international student offices. The ISA at the large institution explained:

A lot of our international students, they struggle because you come to a new country, you don't have any family, you haven't made any friends, you're struggling with your courses, it's very different in the university setting ... we are also trying to see how we can take away the stigma from the idea of having mental health issues

This ISA discussed that they target this indirectly through having other events that bring students together. It was explained:

We try to do it indirectly, its not like we have a mental health workshop, it's "come and meet new people" "Talk to your friends", so we use avenues like Facebook and Tweeting ... just to put the information out there and hope that some of our population is getting that information

Although the ISAs provided significant information based on their experiences, it was interesting to understand the student's experiences and compare to the ISAs responses.

Student participants' share their views 
The results from the interviews with female international students are broken into two major categories with sub themes within them. The categories include experiences before arrival to Canada and life in Canada. Sub themes in experiences before arrival to Canada include: family experiences, school experiences, society experiences, and choosing Canada. Sub themes in Life in Canada include: academic expectations, achieving academic success, experiences during transition to Canada and post-secondary institutions, friend network in Canada, comparing Canada and Nigeria, comparing experiences of male Nigerian international students to female students, student services, impact of finances, investment in international students, and intention of staying in Canada.

\section{$\underline{\text { Pre-arrival to Canada }}$}

\section{Family experiences}

On the topic of their family life in Nigeria, participants discussed that they lived sheltered and stricter lifestyles. They noted that their parents ensured that their focus was on going to school and getting back home. They had little or no social activities and interactions, with stricter curfews for girls, compared to their brothers. Rita (25) said:

Like I had a very sheltered life ... I mean it was basically help your mum in the kitchen, go to school, come home, not much else outside of that

Similarly, Stephanie (21) explained:

Its just a stricter environment for girls than it is for boys

Onyinye (22) added:

My brothers were allowed to go out, my mum would complain they're staying out late but me for example, I go to make my hair and it took me a long time to make my hair and after two hours I was already getting missed calls

Within the household, parents had high expectations and put more pressures on the participants and other female children. Women are expected to act a certain way within the household and 
were expected to keep up certain appearances so as to be socially acceptable. There were assumed roles within the family such as completing household chores, cooking and cleaning. One of the participants mentioned that she cleaned her brother's room and had to check up on him and make sure he was okay, but their ages should also be factored in, because she was older than he was. That said, Rita (25) explained:

I don't think that if my brother was maybe around the same age as I was, I don't think he would have been a kitchen person

Sometimes children observe the roles and relations of their parents and are expected to model the behaviours they see in their mother in order to find a husband. They have learnt from a young age that the father is the head of the family and the mum has to make sure everything runs smoothly at home, even in instances where the mother was the breadwinner of the family. For example, Derin (24) said:

Just even watching my mum as the role model ... this woman, she just has super powers cause she's the breadwinner, so she has to go to work Monday to Friday and Saturday. The weekend where she has to rest herself, she still has to make sure there's food at home. She goes to the market. Market back home is not like doing groceries here, market back home just drains you. She has to be there for like 2 to 3 hours. She has to come back home, cook.

But not all participants saw gender differences in their upbringing. Some participants mentioned that there was not a gender difference within the family with regards to ambition, education, and self-worth. Ijeoma (18) mentions that she did not experience the stereotypes within her family because the first two children were female. However, some participants had different experiences. Adeola (24) said:

Growing up in a house where you're a girl, its a different world, they expect a lot from you. you have to cook; you have to clean. Your goals are not as big as your brother. My dad and company, he's thinking about my brother, like "who's gonna take over" and the rest of us just have to go to school ... and get married 
In Ijeoma's experience, her dad would say things like "is this how a girl is supposed to look" when she's not dressed up. She referred to these comments as sexist but they were comments that she said they would always joke about, and so were considered as minor.

\section{School experiences}

Although they had not completed post-secondary education in Nigeria, some of the participants had heard of female students being treated differently than male students in postsecondary institutions in Nigeria. Some teachers treated female students in a favourable way while some would make sexual advances towards female students and talk to them in inappropriate ways. For example, Rita (25) shared the following:

I mean, even in secondary school too, there were those male profs who like ... not sexually molested or anything like that but just ... I don't know ... they treated females different than they treated males and not in a necessarily good way ... maybe the way they talked to them like in ways that wouldn't necessarily be appropriate here as opposed to back home

Some participants discussed that in secondary school female students were the ones enrolled in classes such as Food and Nutrition and Home Economics. Faith (21) discussed the fact that male students were prone to hitting female students and that it was the norm, "like don't mess up or else they'll deck or slap you and stuff. "It was not a gender equal society. Women were less than men" said Faith, 21.

\section{Society in general}

There are rigid expectations and more policing of Nigerian women in the society. Typically, the cycle involved going to school, finishing university and getting married. Nigerian females are brought up and trained to be wives. Being a wife is considered to be ultimate goal for Nigerian females. Stephanie (21) explained: 
That's why a lot of girls have their education put on the back burner. Because their brothers should be the ones going to school apparently. The experience of a girl should just be creating a wife.

Similarly, Rita (25) said:

I've heard from like my auntie for example where because she wasn't married, she wasn't treated well when she went up to a bank teller or something and this bank teller is also a woman but then she was sort of looked down on because she wasn't married or she didn't have a ring on her finger basically.

Women in Nigeria are also policed on the clothes they wear. As Faith (21) shed light on, it depends on the region because some more wealthy regions are becoming more accepting of women. Women in Nigeria face different experiences in various parts of the country. Faith (21) shared:

When I went back in 2012, my sister and her best friend and I went to the market and my sister's best friend had like a fitted dress and she has a big butt so we went to the market and automatically people were so riled up with the way she dressed because women are not "supposed to dress that way", it wasn't anything revealing to them you're not supposed to wear anything body-con, you're just supposed to look not nice, I guess.

\section{Choosing Canada}

The majority of the participants did not intend on coming to school in Canada. Three out of seven (42\%) participants had the intention to go to school in the United Kingdom (UK) because of familiarity with the UK and having friends and family there. Some, however wanted to go to a country different from their siblings. It was their parents who ultimately made the decision to come to Canada, mostly because some had siblings in Canada. While Canada also seemed to be the best option when compared to the United Kingdom and the United States for safety reasons, permanent immigration possibilities and lower fees. Importantly, parents sent their children to Canada for the quality of education, because they did not trust the Nigerian education system. Thus, would send their children abroad if they could afford it. Others wanted to brag about their children studying abroad. Adeola (24) shared that her dad threw a going away 
party for her going to university for his friends, so he could say "my daughter is going to $\mathrm{X}$ university". Some participants' parents also chose the institution they will be studying in and wanted to choose the programs they studied. Some participants discussed that it was a "Nigerian thing" and that this did not have to do with gender.

\section{$\underline{\text { Life in Canada }}$}

\section{Academic expectations}

Every participant discussed the importance of academics for their parents and themselves mostly because international students come to Canada with studying as the major priority. The women explained that their parents sacrificed a lot and invested a lot of money in their education. They believed that education is the foundation of their future and therefore its very important. Stephanie (21) explained:

It's a lot of money to put down all at once. It's like getting a return on your investment ... being international played the biggest role. Even while in Nigeria education was really important but now the stakes were higher.

Rita (25) noted that:

Like it's the main reason why I came here anyways ... You just think of it as this is what is going to make you successful if you're successful in school. So yea its super important ... you just think of it like the way you're doing is how the rest of your life is going to go basically.

Adeola (24) added:

Success is a big deal. Getting good grades equals getting good job equals getting good husband

In their responses, academic success sometimes meant something different for the parents as compared to them. For Derin's (24) parents, academic success meant getting all the qualifications possible, even getting something higher than a $\mathrm{PhD}$, while to her, it means being determined, knowing priorities and going out to seek help. For Adeola (24) success became more of an internal gratification rather than focusing on grades. Academic success for Faith's (21) 
parents meant finishing university in four years because her older siblings did not finish in four years. Academic success meant the same thing to her but it also meant finishing with a good experience, good grades and strong networks.

There are expectations that come with the importance of academics. Derin (24) for example said:

My parents have expectations that I would not disappoint them [laugh]. Oh my God, African parents. My mum has expectations that I would represent them in a good way ... I would go to school and finish on time ... expectations that when the time is well I would find a husband; I do have that expectation too but at the right time

The expectations parents have sometimes might have a negative effect on their children's wellbeing and until they are made aware of this effect, they keep pressuring their children to do extremely well. Adeola (24) shared:

Success is a big deal for me and it took a toll on me mentally. I was really drained that my psychologist had to call my parents and said maybe they should take off the stress because of the expectations they had ... after all that and my dad realized, he said "drop the courses you have, take one and two and see if you really want to do this".

These expectations come from the Nigerian background and how they have been raised, and what society sees as a desirable child. Being able to talk boldly and brag about your children's achievements and grades with friends was quite common for parents. Adeola (24) shared:

My dad would talk about my GPA over dinner with his friends, he wants to brag about that, so that puts pressure on me to say I don't want to disappoint him.

Similarly, Onyinye (22) said "My parents are Nigerian parents, lets start there, they want to brag about their child". Expectations also rise when parents they themselves had been fortunate to have great opportunities to go to school, even abroad, and get higher education. They want their children to do better than they did. Onyinye (22) for example, said:

My dad was very smart and my grandpa was very poor. It was through WAEC scholarship they sent him to the States ... My dad was the sole breadwinner of the family. My mum and her brother were the main bread winners of their family. They want us to be 
successful. My dad always said he did his masters and wants us to supersede him, if possible.

These expectations might develop due to the perception that Canadian education is better than

Nigerian education. The hope is that Canadian education would help in getting better jobs. Faith

(21) explained that:

Expectations came more from what people think about the country. What Canada can do ... but not necessarily about you ... more about the country and school you're attending. Those are what bring the expectations.

Some expectations also came from being female and feeling the need to work extra hard to be on the same level with boys. Adeola (24) said:

Most of the courses I took and schools I went to, I feel like as a girl I have to work twice to be able to be on the same level with them ... I took it upon myself that I am the only girl so I'm going to get good grades, I don't want the only girl to be dumb

\section{Achieving academic success}

Some participants referred to studying as one of the ways they achieve academic success, while others mention the importance of having friends or people they could talk to or study with to help with school work, especially people that have gone through the same courses ahead of them. Some participants also discussed the importance of having someone to explain the Canadian education system to them because they had to do a lot of figuring out in their first year.

Stephanie, 21: My first year of university was a lot of figuring out and a lot of "oh we thought you knew that" or "well that information was available", available where [emphasis] ... having some kind of guide, if you're failing a course you either do this or drop it.

Faith (21) on the other hand mentioned that she needed to volunteer more to reach her definition of academic success. This is because volunteering, networking and meeting new people are vital in Canada and it will help make those connections. 
Participants discuss that international specific services could have played a huge role in achieving academic success, especially because they came from different educational system than the one in Canada. However, this was not available in their institutions. Onyinye (22) on the other hand expressed gratitude, that although international student services did not provide specific academic help, they provided emotional support which she found helpful as well. She explained that:

They checked up on you sometimes and sometimes maybe knew your grades. If you were struggling, they could direct to help ... they provided emotional support to me where I knew that if I was struggling and needed any help I could go to them and ask them and they would be helpful

\section{Experiences during transition to Canada and post-secondary institutions}

All participants really like the independence they gained when they came to Canada. They are away from their parents and they get to develop independently, without the pressure of living with your parents. Participants also discussed the benefits of having services in Canada such as a writing centre, career centre, and medical centre. In addition, the cultural diversity of Canada allows international students to meet and work with people from different countries. This also opens them up to new experiences, new ways of thinking, and professional and personal growth. Rita (25) explained that she liked:

Learning the chance to work with a lot of people from different countries and I guess those stereotypes you didn't know you had, you start to question them when you're working directly with different people

Onyinye (22) discussed that the opportunity Canada provides for permanent migration is one of the advantages of studying in Canada.

Participants discussed that a challenge they face studying in Canada is making use of the services that are available. Rita (25) says "I think that knowing something is available and using it I think 
they are two different things and I think that my biggest challenge has been using those things that I know are available and will help me". Rita further discusses that she was more motivated to use services when someone else had used it and it worked for them. Participants expressed the challenge of succeeding in school.

Participants expressed challenges of feeling lonely and being alone in their first two or three years of university. Feeling different played a role. Being the only Nigerian or black person in the program or class made things especially difficult. Although they were not really going out or outgoing, they would have liked if they received some help or support with feeling comfortable in a new environment early on in their experiences. Rita (25) reflected that:

I don't know how you can reach somebody that's not really out going, if there was any help for that sort of, just like trying to get people comfortable being in a classroom full of people that did not look like you ... My first two years, it wasn't great because I just went to class, I sat at the back. Half the time I couldn't even hear what the prof was saying ... I don't know how they would achieve that, that would be nice.

Ijeoma (18) echoes this when she said:

Even being black, first time I experienced racism, it was here ... I think letting them know what they're about to experience. The kind of things they'll experience.

Participants also discussed the challenge of attending the orientation week activities planned by their institutions. Stephanie (21) shared that:

Frosh week was intense, it was just like "okay this is too much" and everyone else seemed to be having fun and I was overwhelmed with everything that was going on around me and that's why I pulled out of that circle because I wasn't connecting to it and everybody had moved and I was just dragging behind

Derin (24) expressed being excited to come to Canada but faced a huge culture shock upon arriving and attending her first class. Although she had travelled to the UK a couple of times, she experienced difficulties understanding the professor's accent, difficulties communicating with 
other Canadians especially because she believed she had a strong accent, and she was also always singled out as the African. She also expressed struggling with adapting to the academic system here in Canada, especially with writing. Derin (24) recalled:

I remember there was a professor ... she had to call me one day. She's like "are you sure English is your first language". I was like "wow", I come from an English speaking country and I felt so insulted, like could my essay have been that horrible? And I looked at the paper and read it and I'm like "why would this woman ask me such a question", I felt so embarrassed and then again I didn't give up.

Communicating was discussed by participants as a challenge during transition. Participants found the communication styles in Canada different from Nigeria. This communication challenge had an effect on their overall transition. For example, Faith (21) said:

I find that people here know how to engage in communication and talk to people ... First year wasn't so great because I didn't communicate with lots of people and get those connections. Knowing how to talk to people in Nigeria and then coming here and it's just like "oh my God, I don't know how to communicate with people". It kind of breaks your self esteem a bit.

Similarly, Ijeoma (18) said:

I didn't know I was like that when I was in Nigeria ... I was very loud. It was when I came here that my friends noticed I was a bit more reserved and I didn't have many friends. I didn't know I was introverted in Nigeria. I didn't have to make friends; we just became friends. Here you have to put in the effort of making friends.

Participants faced challenges because they were not aware of the services that were available because most of their focus was on academics, going to school and going back home. This had a lot to do with their background and the pressure they put on themselves and from family. Rita (25) explained:

With the way I was raised, it was just school. School was the only thing you were born for basically. That was your only job. Just to do school and come back home. Any other thing was just a waste of time and I think that definitely had an impact on how I saw things. 
In addition to not knowing about services in general, some participants were not aware what to do with some academic situations they found themselves in. For example, not knowing if they were allowed to drop a course or not. Adeola (24) says 'I didn't know what I could do, if I knew I could drop a course, I wouldn't have failed it. I started and felt like I was responsible for it to finish". Participants also expressed challenges adapting to the education system in Canada, such as dealing with issues such as plagiarism as expressed by Faith, 21.

Participants expressed challenges applying for jobs or co-op placements specifically because they did not have that experience coming from Nigeria. Although there were some support services available to help with resume writing and other job search skills, participants found that some of those services did not take into account international students' experience. Rita (25) mentions "like yes people offered resume help but the resume help was based on 'oh, if you went to Canada you would've done this, that ...' but I did not do any of that coming from Nigeria". Faith (21) said:

I just graduated and the first couple weeks before I got my job, it was the most strenuous process ever because the system doesn't really necessarily help international students. You don't have most of your experiences from Nigeria and even experiences from Nigeria don't really qualify you

In addition, Onyinye (21) explained:

It's just the fact that a lot of things I've been facing like "oh your name", just reminding me that this is not where I'm from or this is not my home country. So its like should I change my name, shorten my name

During their transition, participants discuss the importance of highlighting extra-curricular involvement because most of them come in with 100 percent of their focus on academics. They also discuss that the emphasis should come from the international student offices. Stephanie (21) explained: 
I feel like coming from the international centre would make it a bit more real. When it comes from people who are here anyway, it just doesn't feel like they get it. So if its coming from the international centre that they understand your concerns for school and they say "if you actually do this, you'll do better in school cause you're more balanced" then I think that'll have more of an impact.

Faith (21) also expressed the importance of opening up, as that is something she never really did in Nigeria. She mentioned that it's something she is still struggling with, "I'm so used to coming home and trying to tackle an issue in my head as opposed to going to a therapist or mental health services to destress. The way we handle issues is different.

Overall, participants did not really express that they faced any female specific challenges. However, the challenge of being alone and feeling lonely was attributed to being female. For example, Rita (25) reflected:

I think maybe it has to do with confidence and open thing that I was talking about too. I did find that yea even the ... like the group of friends I was talking about by my third year, they were all international students and they were all female and we just all hung out with ourselves because we were all international as opposed to when I think of the international males in my class, I think they transition much better, I think that they flowed much better than us that had to stick together.

A participant also expressed the challenge of open communications about sex that does not really occur in Nigeria, especially among Nigerian females at a young age. Stephanie (21) explained:

Coming into $\mathrm{X}$ university, from frosh week, the bombardment with sexual innuendo, that was just confusing to me for one. This is coming from an all girls catholic school and I wasn't really going out that much in Nigeria. We hadn't spoken about sex in much detail and loudly and it was confusing how to navigate through the space.

The participants expressed that friends helped with their transition, school resources, asking for help helped some participants, and joining clubs. Stephanie (21) specifically appreciated the support of her Don in first year of university. She shared: 
Her constantly reaching out to me because I think she noticed I was the one person that I'll show up for the meetings but I'm not coming to anything else. She'll just come to my room, reach out to me, see if I was doing okay in school. That definitely helped, warmed me up to other people.

Participants expressed that family expectations also hindered transition. Faith (21) admitted that:

When I was in my first year, I was doing Legal Studies, I had to change to communications. Their expectation for me obviously was to be a lawyer so that was already a stressful moment that for a couple weeks or days just stopped everything. Have to explain why you want to change programs. Them worrying so much just stops you sometimes from doing things.

\section{Friend networks in Canada}

Most of the participants' friendship network was made up of people from their home country. This is because of the level of familiarity and comfort found among people from the same country; and this familiarity helps to reduce homesickness, as they meet their friends at church, international student events, or school clubs. Some participants did not find it challenging making non-Nigerian friends but it was easier to connect with individuals from the same country or similar background. On that Derin (24) shared the following:

I lived in residence, I started even connecting with my Tanzanian housemate before I even got to Canada, through Facebook, and then there was another girl from Japan as well and we would talk. In person I found out that I and the girl from Tanzania we clicked much better because of our roots.

Interestingly, they discussed that having the majority of friends from their home country was both an advantage and disadvantage to aiding to transitioning to Canada and university. Here is how they explained it:

Like you don't feel lonely, there's other people who are new here too like you but no in the sense that it sort of cripples you because then you're not trying to step out of your comfort zone to like meet other people (Rita, 25).

It helped that I came in and there were Africans that had gone through the process and could help point out important resources that were lacking in Nigeria (Adeola, 24). 
Primarily Nigerian and it didn't help me as much in terms of my transition. It was great to have those people I could rely on and I felt close to but in terms of exposing me to the Canadian experience in any way, it wasn't helpful. Not a bad thing but its just what it was (Stephanie, 21).

It also made me have this false sense of security where I thought I was fine and I didn't have to go the extra mile. I still respect the fact that I had people that I didn't have to pick my words though my Nigerian slangs but at the same time, the other experiences and connections I would've gotten (Onyinye, 22).

Although there are benefits to having mostly Nigerian friends, some participants discussed that interacting with non-Nigerians gave them fuller Canadian experiences than their initial circle could. In addition, every participant mentioned that it would be beneficial if there were services available to help international students with meeting domestic students.

\section{Comparing Canada and Nigeria}

A major difference between studying in Nigeria and Canada is the availability of support in Canada. Some participants mentioned that in Nigeria they felt like they had to figure things out on their own. Some participants noted that they did not feel different from boys in high school in Nigeria. However, there might be differences in schools in Canada especially for females in male dominated programs. On this, Onyinye (22) said:

I hear about my friends that are in Engineering for example and how they treat them. My first year when I did some science courses that engineers took. I can say I feel, sometimes you feel injustice, you feel when someone is being racist or sexist to you. Sometimes I felt that when I was in class doing calculus, I could feel the "what does this girl ... does she even know anything" maybe I was just being paranoid.

At the same time, some participants felt that they had more freedom as a woman here in Canada as compared to in Nigeria. Stephanie (21) pointed out that she does not feel the need to dress a certain way or she does not feel forced to know how to cook here in Canada. Faith (21) was also excited for this change and the potential for women's empowerment in Canada because it created avenues for building confidence and awareness. Participants also brought up the increased 
feminist presence in Canada as compared to in Nigeria. This presence allows them to feel more

empowered as women. On this, two participants said:

As opposed to Nigeria where it was like, I remember telling people I want to be a doctor and the first thing they say is "ah, when would you have time to have children" and then I did not think of it as anything because I was Nigerian and all I think about is "I want to have children, it's true". But when I come here and I realize the backwards thinking. People would be like "she went and did school, she finished school and now she doesn't have anybody" (Onyinye, 22).

In Nigeria, they don't really care about those things, they just care about women being housewives and cleaning. In Nigeria I feel I'm expected more to be this uprising and upstanding woman that knows how to cook all the foods, that knows how to clean very well. You can work but just make sure you're taking care of your husband, your husband and family comes first before anything else and here sometimes you're allowed to be you as an individual ... there's just that push for you to be empowered to make sure you're able to stand your own and have yours. There's just a drastic difference (Faith, 21).

Overall, although there is sexism everywhere participants feel that in Canada, there is more support as compared to Nigeria where sexism was common and legitimized. Onyinye (22) for example said:

Unlike Nigeria where it's legal to be under your husband. Its even in pop culture, where the man rapes his wife and there's no scene that addresses it, it moves on to the woman saying "I'm sorry for giving you attitude earlier"

Ijeoma (18) made reference to the fact that in Nigeria, the subordinate treatment of women is so normalized and this leads to female students not realizing they might need support. She explained:

I didn't know I needed support. We didn't have it because it wasn't a thing. It was just how it was. It was here I know that we do need it and there are support services here On the other hand, Stephanie (21) felt that the increased feminist presence in Canada is not relatable.

I could explain with a course I took, women and work, the professor asked all of us to give our perspective on ... I don't really remember what it was, I wrote now my answer feeling all proud and feminist ... and she read the answer out and she was like "no, this is exactly what I'm trying to address in this class" and I was looking at her like "girl, you 
don't know what you're talking about'. From that point there was an understanding of the impact of culture, world views impact feminism.

She added:

The whole relationship dynamics ... its like the little things like that, those aren't my concerns, my concerns are the larger scale, there are people who still can't vote, can't drive, there are people living in secrets because this person is hitting them constantly or they've been raped ... but when you're in a society that has granted those things, its easier to focus on the smaller details and to worry about those things.

\section{Comparing experiences of male Nigerian international students to female students}

The majority of the participants were not sure what their experiences as female international students from Nigeria were like compared to those of male international students from Nigeria, mostly because they were not men they could not relate or assume. They assumed their experiences would be different but were not so sure how. However, Rita mentioned that she thinks that male students are more under pressure to come home, although she's feeling that same pressure. In addition, Rita (25) speculated on the difference between confidence found in male Nigerian international students and female Nigerian international students:

I think that the males tend to be more open to being friendly with people from other countries and maybe that helps them transition easier and fit better into the Canadian society or something but I don't know ... I'm just looking at my circle of friends and I feel like I find that males are ... they just go right into it. Its a little bit slow for the females.

There are also assumed differences between choice of courses for males compared to females.

Stephanie (21) said:

I think there's a pressure for them ... being in the science related thing, architecture, engineering and for the girls its more law ... the pressures are different but very similar.

Male international students are also perceived to receive more money from their parents than female international students. For example, Stephanie (21) shared the following: 
Boys also get more money than girls do. Maybe those differences come out of how parents are reasoning how the person is going to live. Maybe thinking the boy would have other people depending on him for some extra money.

\section{Student Services}

Six out of seven $(86 \%)$ of participants used international student services mostly for immigration help such as renewing their study permits, temporary resident visa or getting a work permit. These participants are very satisfied with the immigration support they received from their institutions. Although they use international student services mostly for immigration help, Rita sees the international student offices as a home base where students could always go to for any help they needed.

Participants mentioned that they utilized international student services mostly for immigration help because it was an important need for them as compared to the other services that were available. Some participants felt comfortable seeking help for immigration needs but not for other needs, such as personal issues. In addition, some participants did not utilize international student specific services because they believed they will end up meeting more international students and they wanted to meet non-international students, instead.

It was discussed that international students do not make use of services because they feel confident in their ability to navigate the new environment or they get so comfortable with their group of friends, they forget to experience university life. Participants realized that when they ultimately got to use the services and by the time they knew all the information they needed to know, it was too late. On this, Stephanie (21) said: 
So because you think you know you just don't ask and when you need to ask, you haven't made those people your first contact. No relationships built with the international centre and going to them seems like a last resort.

Similarly, Faith (21) said:

Domestic students know what to look for when they need these things but international students sometimes don't and don't know who to meet besides the international office

Although they barely made use of university wide services, they believed they were helpful and filled a demand. They found services like the academic writing centre, the career centre, and medical centre helpful. Some participants stated that they did not find their Registrar's Office helpful.

Overall, participants felt that their needs were met to a certain extent but not perfectly. On this, Stephanie (21) said:

To some degree. I feel like information is just everything. If you don't know what was out there, you're powerless. I don't feel like there was enough information on what the school has to offer me. Having that knowledge is the one way my needs weren't met.

Participants also felt that ultimately some of their needs are beyond the capacity of the institution and are more of a wider systemic problem. Faith (21) explained it like this:

There's still that you're an international student, you can't get much here, you have to go back home ... institution wise, I feel like there's so much they can do, they've provided the services. It doesn't change the fact that I guess cause you're an international, you're not from Canada, people are going to look at you like, whether you have all these things stacked on your resume, people are always going to look at you as an international student.

\section{Impact of finances}

Participants discussed the fact that finances play a significant role in academic success and in their transitioning to Canada. Although none of the participants faced major financial difficulties while in school, they are aware of the role finances play in success in university and in Canada as a whole. Rita (25) put it this way: 
I mean, I was comfortable, I wasn't having to work like 40 hours a week and still go to school so definitely. I know for people who had to work like it was really hard for them. Like maybe ... they definitely weren't getting as good grades as I was and its not as if they weren't smart, they just had to work. so definitely being stable helped.

Participants were grateful for the financial support their parents provided while they studied.

They would remind themselves of how much they were paying as a motivation to do well in school. Financial dependence on parents also increased student's motivation to find a job. Derin (24) admitted:

I am so grateful for my mum ... if you can't even afford to go to school here, you can't pay tuition, you won't be here in the first place ... if they didn't have the finances to support me, there's nothing they can do about it.

Similarly, Adeola (24) said:

It did play a role with my motivation, "Oh my God, my parents are spending this amount of money so I needed to do this".

Participants made reference to financial support programs such as international work study programs that allow students to work on campus for about 10 hours a week. The option of having co-op programs also assisted students in getting financial support while in Canada. They also made reference to some bursaries or scholarships they believed were available. There were also food banks and grocery supports available to international students, as long as they are aware of them. Although the participants could identify some services that are available, they were not fully satisfied with them. It was often noted that financial supports for international students were not enough compared to those for domestic students. Here is what some of them said:

For international students, we had to do more work to get those things ... I remember when a girl in my class was telling me "oh she just had to submit some documents", I had to write a freaking essay to prove that I have financial need, attach this, I had to get references, this girl didn't have to get anything ... I was so pained; I was like oh my God this is so unfair (Derin, 24). 
I remember asking Dean why there are no grants for international students, [he/she] said because parents are paying taxes and they don't want to give OSAP because international students might not be accountable for it. But I'm not asking to borrow but I'm asking to give me the money because it'll take away a lot of mental, physical, emotional stress from me if that could happen. The financial part was a motivation, you don't want to feel like you're wasting money (Adeola, 24).

Only 20 international work study positions available and there are like maybe over 1000 international students, imagine 1000 international students rushing for those 20 jobs (Faith, 21).

I don't think they want it to be equal, they probably want to remind us that you're not domestic. So maybe more but I don't think they want it to be equal. It probably should cause it's harder for us here (Ijeoma, 18).

It was often mentioned that more grants and opportunities should be made for international

students. For example, some participants stated:

Create more grants. Help us, instead of just using our tuition fees to build your school ... try and create some programs to get the return of the money we're putting in. and also giving us first priority in a lot of things, since we're paying a lot, we pretty much fund the institutions. Giving us first priority in job applications and things like that (Derin, 24).

Things happen, your parents might plan to pay but the exchange rate or economy changes and then that's why we should be able to help students to help complete (Adeola, 24)

We're paying all this money basically for the school to run, you can't just remove some money from the money you already get just to say here are these other 20 jobs for more international students to work. I feel they can do more and they're just not doing anything (Faith, 21).

In sum, the students interviewed felt that more information should be made available regarding the financial support available to international students.

\section{Investment in international students}

A majority of participants thought that their institutions are not investing enough in them as international students. Five participants expressed frustration: 
Nope. they think you're returning back to your country so they don't want to invest that much in you. They don't see that return for international. They don't specifically say I going to meet international student needs, I'm going to invest in them, its all about your own students and that's it (Adeola, 24).

Not as an international student, as a student sure but as an international student, not so much ... there's a lot of fighting for domestic students, a lot of lobbying. Let's say lower fees. If you lower your fees, someone else would have to pay, often times that ends up being me (Stephanie, 21).

International students we pay so much money. Valid it's not our country like we pay so much money but there's this little baby section of international, like here are the international students. We are not necessarily integrated into the system as a whole, its just always, those are the international students maybe one day they'll stand up and go back to their country. Yes, they provide services they provide everyone else, it's a case of equality versus equity ... sometimes I feel like we're just a money bag (Faith, 21).

They tried their best ... I feel welcome, I don't feel like an immigrant, they don't make me feel different. $\mathrm{X}$ institution, no as the organization, International team is seen as this other. I feel like the International Student Advisor office was underfunded (Onyinye, 21).

No. I think they could care less as long as you pay tuition (Ijeoma, 18).

\section{Intention to stay in Canada}

Participants had varying responses regarding their intention to stay in Canada after completing their program. Some participants do not have a plan because their plans depend on their current permit, as explained by Stephanie (21) "I'm staying here for the next 3 years at least and if things work out. My current work permit only lets me be here for the next 3 years, so we'll see". Some participants plan on getting their Canadian citizenship and will likely end up staying in Canada for the rest of their life. Most will likely decide after they receive their Canadian citizenship. While some plan on staying for about 10 more years, to work and get experience in Canada. On the other hand, Adeola (24) intends on staying until the end of her Post-Graduate Work Permit, which ends at the end of three years. She sheds light on the constraints immigration status puts on individuals. She added that the complicated process just to get 
Permanent Residency or Canadian Citizenship discouraged her from staying in Canada. She explained:

When I came, the next big thing everybody started saying was PR, you need to get your PR and I felt a lot of my goals were constraint and within that PR boundaries and the moment I realised I can do anything outside of that, I stopped having interest in Canada. So I'm staying here for 3 years because I have a 3 years work permit but I might even leave in September or next year depending on how I feel ... but I'm not going to be in Canada long term, I'm not really aiming for the citizenship or the PR.

I got so overwhelmed with wanting to stay in Canada that when I got to that point, just saying "you know what, my life shouldn't revolve around this" I just lost interest. I'm going to miss all the good services or I'm willing to just go, or maybe go to a different country and not Canada. But I don't think I should just get any job just to get PR

However, majority of participants want to give back to the Nigerian community even if they do not plan on moving back. Some participants do not want to move back to just join the work force but they want to make an impact on the society. That said, family and food are motivating factors of moving back to Nigeria. In addition, participants discussed having more opportunities moving back to Nigeria compared to here in Canada. Derin (24) for example said:

The way the system is structured, all your money is going into taxes. Back home, our parents were able to send us here, there's money back home.

They also made reference to the lack of discrimination in Nigeria, compared to here in Canada:

That discrimination thing going on, you don't have to experience it, you're among your people, we're all black, we all share the same skin colour. That whole systemic racism thing pulls as a barrier for you to move forward or moving to top positions (Derin, 24).

The services they have received here played a role indirectly because the availability of support here in Canada has motivated some to want to stay behind in Canada. For those who decided to move back to Nigeria, the lack of services in Nigeria made that decision harder. For example, Stephanie (21) was torn:

I am not unhappy here, if I felt like I was being pushed out I'd be a bit more eager to go back but I feel very comfortable here 


\section{Discussion}

Nigerian international students represent the $11^{\text {th }}$ largest group among the international student population in Canada. Nigerian international students also represent the largest group in the international student population among African countries. These students encounter challenges in their adjustment to Canada, a country very different from their home country. They have to adapt to a new academic system, language, and culture, but they also spoke positively about their experiences.

The goal of this study was to understand the experiences and needs of female international students from Nigeria studying in Canada. The semi-structured, open-ended interviews allowed participants to reflect, in their own words, on their experiences, perceptions, actions and concerns regarding their settlement experiences in Canada and in Canadian institutions. The interview process also allowed ISAs that have experience dealing with international students to share their knowledge regarding programming and service provision.

This section will discuss major findings of the research in relation to existing research and identify recommendations for the ISAs and service providers at the institutions who work with international students, especially female international students from Nigeria. The findings are categorized into transition experiences and perception of services, with sub-themes within each category.

\section{$\underline{\text { Transition experiences }}$}

This section discusses the transition experiences of Nigerian female international students in this study. The sub-themes in this section include personal and professional growth, isolation and loneliness, academic challenges, and female specific experiences and needs. 


\section{Personal and professional growth}

Although majority of the participants in this study did not intend on coming to Canada, they described their opportunity to study in Canada as a pleasant one. Nigerian female international students described both positive and negative experiences in their experiences studying in Canada. Participants appreciated the independence they receive when they moved away from their parents. They are able to grow independently as young women away from the pressures exerted by their parents. They also expressed appreciation for services such as the writing centre, career centre, and medical centre as these services aided in their professional development as students; and this finding was much like Chan's (2006) study on Mainland Chinese female international students. Participants also discussed that they appreciated the cultural diversity of Canada because they have the opportunity to meet and work with people from different countries. They found that this helped them to become more open and culturally sensitive, and as a result they developed new ways of thinking.

Participants also talked about their negative experiences such as experiencing feelings of loneliness, confusion, unawareness about services, exclusion, academic challenges, difficulty communicating with domestic students, and difficulty finding jobs. These findings confirmed the results of other studies on adjustment difficulties of international students (Pidgeon \& Andres, 2005, Faid-Douglas, 2000, Hwang et al., 2014, Popadiuk, 2000)

\section{Isolation and loneliness}

Although the majority of the participants expressed that they received social support from a variety of resources including Nigerian friends, class members, and services on campus, most Nigerian female international students in this study reported experiencing loneliness, isolation, culture shock, and difficulties forming friendships with domestic students. Participants attributed 
feelings of loneliness to being the only Nigerian or black person in their classrooms or environments. Loneliness was also attributed to personalities, as some participants were not as outgoing as other students were or some were shy. One of the ISAs interviewed during this research also confirmed this. This is also similar to research carried out by Chan (2000), in which participants indicated that they found it easier to relate with Nigerian students and other international students as compared to developing friendships with domestic students. Likewise, Pidgeon and Andres (2005) found that international students felt more familiar and comfortable with people from their home country. This familiarity helped to reduce homesickness and the culture shock they experienced. However, they found that although interacting with Nigerians brought about comfort and familiarity, it could also bring about some disadvantages. They found that interacting with only Nigerian students limited them from having a full Canadian experience because they could become stuck in their comfort zone; while some also felt that it created a false sense of security, in which they thought they did not have any needs, when in fact they did. In this context, Popadiuk (2000) found that isolation and loneliness are the two most significant predictors of how well international students will cope in their new surroundings. My research confirmed this because once international students found that they were becoming too comfortable communicating with only other international students, they strove to make domestic friends in order to gain a fuller Canadian experience. Some participants found themselves more satisfied with their transition once they interacted with domestic students and people from other backgrounds.

\section{Academic challenges}

According to research by Faid-Douglas (2000), academic success is the number one priority for international students. This was found to be true in my research carried out for this 
study. Every female international student in this study discussed the importance of academics for their parents and for themselves. International students from this study came to Canada with one goal, academic success. They explained that academics are very important because of the sacrifice their parents make to send them to school in Canada and especially because it costs a lot of money to study in Canada. Nonetheless, participants discussed differences in the meaning of academic success for themselves and their parents. For parents, academic success means getting all the qualifications possible, finishing university in four years, and getting all A's. While for the female Nigerian students' academic success meant similar things but also being determined, knowing priorities, seeking help, getting good experiences, good networks, and internal gratification. In other words, success meant more than just grades.

The importance of academic success brought many expectations for female international students from Nigeria. These expectations came from their parents and themselves. They were expected to do very well because a lot had been sacrificed for them to receive a Canadian education. Participants also discussed that just being Nigerian brought about high expectations because a characteristic of a "desirable child" in that society is excelling in school, so parents could brag about their children's success. High expectations also had effects on the students' transition, as they generate great pressure and stress to the extent that it affected one participant mentally. In this context, Faid-Douglas (2000) found that female international students face more difficulties adjusting to university as compared to male international students. Although an actual comparison of men and women's experiences could not be made through this research, female international students from Nigeria were found to face significant challenges adjusting to post-secondary institutions.

Female specific experiences and needs 
As female international students from Nigeria, participants in this study shared their experiences as females growing up in Nigeria and some offered a comparison with growing up in Canada. First, within the family, participants experienced living a more sheltered and protected lifestyle while in Nigeria, such as having strict curfews and for those who had male siblings, having stricter curfews than their brothers do. The sheltered lifestyle the participants faced could be related to safety concerns for females growing up and living in Nigeria. One of the ISAs interviewed referred to this by discussing that the majority of international students who were accompanied by their parents during orientation were female international students. As discussed by Oniye (2013), the students also made reference to certain ways they were expected to act as women, such as cooking, cleaning, dressing a certain way. These are expectations they see among women in the society, such as mothers, and they are expected to emulate that. Although Oniye (2013) observed that women tend to accept negative self-fulfilling prophecies and believe they are the inferior sex, participants from this study did not feel inferior to their male siblings. They also did not express feelings of inferiority women regarding their self-worth, ambition or desire to pursue education. However, Oniye (2013) emphasizes the importance of exploring class and privilege in cases of equity. This study comprised a small group of female students from Nigeria whose families could afford to send them to school abroad regardless of gender. Oniye (2013) discussed that most families that cannot afford to pay the cost associated with education would prioritize male education. Some participants did mention that certain occupations are viewed as more suitable for women and being a wife is considered the ultimate goal for Nigerian females. Whenever a participant mentioned she wanted to be a doctor, she had to be reminded that being a doctor takes a lot of years and is very time consuming and she might not be able to be a doctor and have a family. This result is consistent with Oniye's (2013) research. 
According to Allanana (2013), "the subordinate status of women vis-à-vis men is a universal phenomenon, though with a difference in the nature and extent of subordination across countries" (p.133). This highlights the fact that sexism is not an issue found only in Nigeria, but Nigerian society might not be providing support to deal with this. Aihie (2009) discusses that in Nigeria violence and abuse towards women is tolerated and excused; this is one of the reasons why some participants' parents wanted them to study in Canada. They experienced male teachers treating female students differently as compared to male students, as a participant said "in ways that wouldn't necessarily be appropriate here". The issue of gender-based violence was also discussed as something that was normalized within and educational setting in some Nigerian institutions. The participant that experienced this explained that it instilled fear in her; fear of boys in her class or even fear to have conversations about it. The lack of social structures to eliminate gender-based violence can affect how women view themselves and how they view men as well (Esere et al., 2009). They did not receive any support from the institution as it was so normalized and they were forced to turn to other boys to "protect" them. This experience is not limited to students in secondary school because violence against women is normalized within Nigerian society as noted by Aihie (2009).

Aihie (2009) discovered that women in West-African societies do not know if they had experienced abuse or not. Similar results emerged in this study; the unfair treatment of females in Nigeria is so normalized that female students from Nigeria sometimes do not realize what their needs are or the fact that they need support. In the earlier sections, it was discussed that participants felt lonely and isolated. This is a common experience with international students in general and female international students in particular, as mentioned by Faid-Douglas (2000). It was mentioned by a participant in this study that male students from Nigeria tend to be more 
friendly, confident and open and this eases their transition to Canadian society and university as opposed to herself and other female students from Nigeria. This confirms work by Aja-Okorie (2013) and Oniye (2013). They discuss the dynamic that inequality experienced by young women creates an inferiority complex in many of them. They accept the stigma that they are the inferior sex and this is expressed in their level of confidence as compared to those of Nigerian men (Oniye, 2013). This is reflected in the level of confidence felt by female students when they take courses with male students and they feel insecure because they are girls.

Despite the challenges they experienced in the migration process, transition to living in Canada and being part of a Canadian post-secondary institution, Nigerian female students in this study feel more freedom, liberty, and empowerment. They feel safer, secure with support, and feel that they do not have to conform to the expectations that Nigerian society places on women. However, coming into this society, they still face some challenges as women. The challenge of adapting to the increased feminist presence and identifying with the feminist movements in Canada was emphasized. Students in this study come from a society different from Canada; some injustices experienced by women in Nigerian communities might differ from those experienced by women in Canadian communities. In addition, the mechanisms put in place to address these injustices differ in both societies, as discussed by authors (Oniye, 2013; Aihie, 2009). They come into Canadian society and have to adapt to this difference and this was expressed as a challenge. This form of feminism which sits in contrast to the experiences of students highlights precisely the point made by some post-colonial feminists. Post-colonial feminists stress the importance of addressing intersectionality and understanding the experiences of other women, and in so doing, not judge them by western measures or standards. 
The results from this research shed light on the importance of understanding intersectionality and of considering multiple aspects of individuals, this is rooted in and emphasized by post-colonial feminists.

\section{$\underline{\text { Services }}$}

International student offices provide support to international students to aid their transition to university and Canada. They provide both pre-arrival support to students and support during their time studying at the institutions. International students also have access to services provided by the institution to their whole student population. This section discusses the perception and implementation of services from the points-of-view of the International Student Advisor's (ISA) and the female international students. The themes discussed are service usage, gender, and internationalization. This section will conclude with recommendations for services raised by female international students from Nigeria.

\section{Service usage}

My research confirms that international student advisors or offices are one of the first points of contact for international students when they have concerns. This is because most of the pre-arrival communication comes from their office; therefore, international students would reach out to them if they face any concerns. Overall, international students in this study believed that services currently provided by institutions are important and play a significant role in student development. That said, literature shows that international students infrequently make use of student services (Zhai, 2002; Mesidor \& Sly, 2016). This was confirmed by both ISAs and international students in my research. There are various factors in the literature that explain the underutilization of services by international students. Mesidor and Sly (2016) discuss self- 
efficacy found among international students. Some international students believe in their ability to succeed and this brings about feelings of independence and belief in their ability to navigate their new environment. Participants in this study (ISAs and students) confirmed this reasoning. International students in this research utilized their support network as help sources, rather than turning to international student services staff because they felt more comfortable talking to their friends. Research by Zhai (2002) found this and emphasized that international students did not think staff members would be knowledgeable about their problems. Students in this research shed light on the unawareness of services available. This unawareness limits their ability to utilize services. Zhai (2002) discusses that international students come from countries where such services are not normally available; therefore, students are not familiar with them and are unlikely to use it. At the same time, results of this study confirmed findings from Zhai's (2002) study, which found that international students frequently utilize international student offices for immigration help, such as study permit, visa and other applications; and participants in this study were very satisfied with the support they received.

Female international students in this study raised concerns specifically with financial services and orientation programming. Although none of the participants faced or are facing financial difficulties while they are in school, they discuss that finances play a significant role in their transition to Canada and post-secondary institutions. Overall, finances play a huge role in the experiences of international students (Zhai, 2002; Pidgeon \& Andres, 2005). Financial challenges faced by international students and their families are significant but are not taken into consideration by service providers. When applying for a study permit, international students have to prove they have the financial ability to pay their fees and pay for their trip back home ("Determine your eligibility", n.d.). Therefore, there are assumptions that every international 
student is wealthy and can afford education in Canada. Various circumstances arise and bring about financial difficulties for international students. However, literature highlighting the financial challenges of international students is lacking. Although participants in this research did not face significant financial challenges, they referred to their parents dealing with the Nigerian economy and the impact of the exchange rate of Naira to Canadian dollars on their parents. In this context, the Nigerian President, Muhammadu Buhari discussed that Nigeria cannot afford to sell foreign exchange to parents to fund education for their children abroad (Aderinokun \& Soniyi, 2016). Parents of students studying abroad need to pay tuition fees, therefore there is a high demand for foreign exchange, however, this demand is negatively affecting the Nigerian economy (Aderinokun \& Soniyi, 2016). The President ultimately ruled that Nigeria would no longer sell dollars to parents to pay fees of their children abroad. However, parents could purchase dollars outside the official window but it is very costly. It was mentioned that although their parents do not always discuss the challenges they experience, the students are concerned. However, some participants mentioned that their parents have been late on their payment of fees or allowances to purchase books. This study confirmed findings in research by Pidgeon and Andres (2005); participants were not satisfied with the financial support provided to them, and international students typically had to go through longer processes to receive financial assistance.

Lastly, orientation or frosh week is an important part of the university experience for students in general because during this time, they get to meet other students and get to learn more about the institution and services provided by the institution. Although Pidgeon and Andres (2005) discuss the positive reviews of Orientation week by international students, participants in this study expressed feeling overwhelmed and uncomfortable with Orientation and Frosh week 
programming held by institutions. Most importantly, this programming is intended to provide vital information to aid in the transition of new students, however, some students feel disconnected, they do not attend or stay on their own, which in turn affects their awareness of services.

\section{Gender in service provision}

A problem with service provision for international students is homogenizing international students and treating them as one group (Edwards-Joseph \& Baker, 2014; Pidgeon \& Andres, 2005). The experiences of international students vary based on culture, social and economic capital, academic experiences, gender, personality, etc. (Edwards-Joseph \& Baker, 2014; Pidgeon \& Andres, 2005, Bonazzo \& Wong, 2007). This issue was evident in this research; one of the ISAs interviewed mentioned that programming design for international students takes into consideration general issues that international students face because they assume that international students have the same experiences and challenges. Therefore, they look at the students first as international students before other issues are explored. This is problematic as discussed by Bonazzo and Wong (2007). The authors mention that literature on international students lump all international students into one category while ignoring in-group differences. This results in difficulties in accurately addressing unique needs and challenges. In the study, it was clear that for ISAs, cultural differences had come to mind but gender differences were rarely thought about. This is confirmed in literature that discusses that culture is usually the most obvious difference that is taken into account when studying international students (Bonazzo \& Wing, 2007; Faid-Douglas, 2000). However, Faid-Douglas (2000) similarly noted that gender is a very important variable to study as compared to only focusing on the idea of being culturally different. This sheds light on the importance of intersectionality, not focusing only on one 
variable, but instead seeing how different experiences and contexts interact to produce diverse outcomes. Exploring the intersection between gender and culture brings about a different perspective. It is important to acknowledge differences experienced by female Nigerian students and not just Nigerian students or just international students.

In agreement with current research (Faid-Douglas, 2000; Bonazzo \& Wong, 2007), this study shows that that international students face specific challenges both because of their home country and gender. The implementation of female specific programming will empower female students by instilling confidence in them as they know that their needs are valid and they could share with other female students experiencing similar situations. Faid-Douglas (2000) discusses that female role models encouraged and pushed female international students to succeed. However, this impact is not discussed extensively in the literature. Limitations such as size of campus, resources and capability limits the opportunity to provide specific programming for international students. There are discussions around disregarding gender in programming, especially to ensure inclusion of all international students. However, it has been found that female international students face specific challenges compared to male international students, therefore, it is important to address the female specific issues also. This should not be considered as being discriminatory. To conclude, Deem (2003) quotes, "whatever is represented as genderneutral is likely to obscure the power relations of gender" (p. 243).

\section{Internationalization of services}

International students contribute to the Canadian economy and bring a diverse set of experiences to institutions and their community (CBIE Research, 2015; Alboim, 2011). International students form an integral part of the internationalization of institutions, and institutions in Canada have increasingly become aware of the benefits of internationalizing their 
institutions (CBIE Research, 2015). Internationalization is not a new term but is being used more frequently in the past 20 years. Internationalization has various meanings and could refer to increasing international activities for students and teachers, international partnerships and projects, delivery of education to other countries, etc. (Knight, 2004). Internationalization defined by Knight (2004) is "the process of integrating an international, intercultural or global dimension into the purpose, functions or delivery of post-secondary education (p.11). This definition encompasses the results from this study.

An advantage of an internationalized campus is the development of friendships between international and domestic students. However, this research, in conjunction with other research shows that this is lacking. Although institutions have internationalization strategies, participants in this study find it to be lacking. Regina (2003) mentions that institutions are now “international" in awareness but few are "international” in practice. CBIE Research (2015) backs this up by highlighting that ethical internationalization emphasizes the importance of international student integration. The feeling of exclusion was emphasized by participants in this research; they discus that although they pay so much money to study here, institutions have the international office, which is seen as the only space for international students. As one participant said "there's this little baby section of international ... we are not necessarily integrated into the system as a whole". Female international students in this study emphasized that they wanted more contact with domestic students and the various cultures. The interaction with other cultures and the sharing of one's own culture enriches the international student experience.

In this study, the importance of receiving academic support from international student offices was emphasized. This is especially important because of the difference in education backgrounds of international students. Pidgeon and Andres (2005) discussed the importance of 
internationalization of classrooms by faculty members by acknowledging the difference in education systems of international students. The authors maintain that it will bring about a better academic experience for international students. Participants noted that international student offices providing support or collaborating with other offices to provide academic support would have been beneficial because they would be coming from different educational backgrounds and this would prove that those differences are acknowledged. This was also found in research by Zhai (2002). Ultimately, the integration of international student in every aspect of the institution (not only academics) improves the overall international student experience.

Overall, female international students from Nigeria in this study felt that their institutions were not investing in them as international students. This study confirmed Kamara and Gambold's (2011) point that international students are disappointed with the level of support they receive from their institutions. They believed they were invested in as student but not as international students. This was corroborated by Gates-Gasse (2010) who discussed that universities spent less on international students than on domestic students. The students expressed that they are only viewed as a source of income and institutions do not care as long as they pay tuition. Gates-Gasse (2010) confirms that this mentality is true, as international students are seen as sources of revenue. The author goes on to say this dehumanizes them and affects how international students are viewed. Results from this research confirms this. International students from this study have strongly expressed that they feel that their needs are not recognized and not considered by their educational institutions solely because they are international and not from Canada. In this vein, participants in this study made reference to the structural challenges that serve as barriers to the international student experience, such as the shortage of staff or underfunding of international student offices. 
Although participants were not fully satisfied with the services they receive from their institution, the services they received at their institution either positively impacted their decision or had no impact on their decision to either stay or remain in Canada; that is, it did not negatively impact their decision. 


\section{Recommendations}

International students participating in this research primarily came to study in Canada to learn from Canadian educators. During the process, they became interested in Canadian culture, and other cultures and wished to share their own culture with other students. They were open to new ideologies and interested in improving conditions in Nigeria. But most importantly, they sought to improve themselves. Results from this study are important for service providers at post-secondary institutions, particularly those who provide services for international students and female international students. International Student Advisors, academic advisors, faculty members, and staff members can use the experiences and stories from students shared in this study to develop and provide programming for the unique needs of female international students.

Overall, international students in this study are requesting institutions to take internationalization more seriously. They want to be included in all aspects of the institution and feel that their experiences and needs are being considered when it comes to service provision. During program development and service delivery for international students, service providers should be aware of and be sensitive to the cultural differences between international students' home countries and the Canada. Especially for female international students, service providers should recognize and take into consideration the internalization of cultural norms surrounding gender among female international students from Nigeria as discussed in sections above. Majority of the recommendations discussed below emphasize the importance of cultural awareness and sensitivity in service provision and for the most part, do not require a lot of resources to implement.

The results of this study strongly indicate that service providers should learn what some of the specific needs of international students are by talking to senior international students 
and engaging them with peer support, mentoring and running various workshops for international students. It would be beneficial to incorporate female to female mentorship opportunities or activities for international students from the same region. This is because these female students understand the transition experiences from their home country to Canada and with support from staff members, they will be able to provide beneficial support to new female international students. This can be implemented in areas such as emphasizing the importance of more introductory information provided about Canadian education and culture. Introductory information would explain to students the academic expectations that will be placed upon them as students in Canada. This information would be even more beneficial if it is compiled and drafted by international students who themselves have gone through the experiences. It would be beneficial to provide students with information regarding classroom etiquette, contacting professors, speaking in class, and how to deal with academic challenges. Especially female to female support, as mentioned above. This will allow students to engage in dialogue about differences in cultures and approaches between Canada and their home countries. Students would feel more confident in the support they receive if it is coming from peers and service providers who are aware of and take into consideration these differences. Female international students in this study recommended that the international student office should play a role in the hiring of support staff who provide assistance to international students especially in the areas of academics, as mentioned above. This would ensure that someone who has similar experience or an international experience, or is bilingual would be available to provide support to international student. Such additions would make students feel more confident and inclined to utilize the support. For instance, including international students themselves in service provision as volunteers or student staff. This provides more employment and volunteer opportunities for 
international students. It also increases their exposure to Canadian culture, brings about feelings of inclusion in their institutions and provides resume building opportunities for the students. However, this will not only benefit current upper year international students but it will also be beneficial to new incoming international students.

In addition, most participants in the study felt that they were excluded from university experience as a whole as international students and felt that they were not given the opportunity to contribute to Canadian society as they would have liked to. Although some institutions have events like "international student day" or "Mother language festival" that celebrate international students, participants feel that having those events once a year or once per semester is not enough to express and share their culture. Participants also recommended having events organized by domestic students specifically for international students to provide opportunities for cultural exchange. It would also allow international students to be open to meeting domestic students and vice versa. Having more events or opportunities for involvement would be beneficial for international students. Likewise, international students should be encouraged to participate in extra-curricular activities and events planned for both domestic and international students. When this information comes directly from the international student office, they believe the individual understands international student challenges and would not mislead them. However, it is also important to keep in mind that some types of activities and events can be overwhelming for international students due to initial transition challenges such as cultural differences (for example, Frosh week).

International Student Advisors should have mandatory check-in periods for international students to attend. The purpose of this period would be to reach out to students to ensure they are doing well. This check-in period would especially be beneficial to students who are shy and 
more reserved to have the opportunity to talk to an ISA when they would not have otherwise. The implementation of this service would especially benefit female international student population from Nigeria because participants in this research expressed that female international students tend to be more reserved and shy as compared to male international students. A participant emphasizes the importance by mentioning that she might not have liked the mandatory aspect of it but it definitely would have helped her transition. This would also increase the opportunity to discuss mental health among international students. The participants mentioned that mental health should also be prioritized as a support for international students.

Participants also recommended that the international student support office should host more events in partnership with other departments on campus that provide services to all students. For instance, events geared towards academic success would be very useful because within the first months of year of arrival, international students are focused on their academics, and this would be a way to attract them and gain their interest and trust. Participants also discuss the importance of having networking events hosted either by the international student office or in partnership with the career office but specifically for international students. Bringing in past international students who are working in the Canadian system would be motivating for international students. Events hosted by the international student office would attract international students

A major recommendation made by international students in this study is the importance of raising awareness about the services that already exist in their institutions. International students feel that they are unaware of services provided by their institutions. Although some services are mentioned at the beginning of the year, it is difficult for them to remember all of this information when they are bombarded with a great deal of new information. They also 
mentioned that more explanation regarding services should be provided. This means providing more information on what the services do and how it would benefit the students; and including testimonials by students would help. This would motivate students to utilize those services more fully because they know they have been used by fellow students like themselves. Participants in this study mentioned that there should be an increased awareness about international students and experiences of international students on campus. Participants felt that international students and domestic students are disconnected within their institutions.

Regarding financial support, female students in this study recommended the creation of more grants for international students. They would also like to receive first priority while applying for grants and bursaries. This is because they feel that they have very limited opportunities available as compared to domestic students; and they thought there should be a designated number of bursaries every year willing to be given out to international students. 


\section{Conclusion}

The purpose of this study was to understand the experiences of female international students from Nigeria, to examine the gender specific needs of these students and explore if current services provided by post-secondary institutions meet these needs. Overall, Nigerian female international students in this study experienced challenges transitioning into university and Canadian society. It was found that some of these challenges are not unique to this population. However, the background of female Nigerian students is unique they and bring their own unique experiences with them. For instance, although academic challenges are not unique to female Nigerian students, the type of academic challenges they face and the reasons they face them are a result of their upbringing and experiences in Nigeria. Gender indeed plays an important role in the experiences of international students from Nigeria. There are normal needs of every female population that female international students from Nigeria are not aware of, or do not consider as needs because of normalization and lack of adequate services in their home country. For this and other reasons, there needs to be a better internationalization strategy implemented by institutions because international students want to feel fully included in the university community. Institutions should not neglect gender as important for programming and should begin to have those discussions with their female international students about their experiences and needs. The recommendations provided in this research overall emphasize the importance of cultural awareness and sensitivity in service provision for international students.

Although female international students from Nigeria face challenges transitioning and integrating into the Canadian society and post-secondary institutions, they are very strong and resilient. They realize the importance of education, the sacrifices their parents make to send them to Canada to study and the privilege they have. Half of the participants in this study have 
completed their degrees and the other half are on their way to completing it. Although they faced challenges, no participant made reference to dropping out or going back home. Their strength should be recognized.

A limitation of this research is that it is not generalizable to the whole female international student population or other Nigerian female international students. Major Research Papers are limited in time and scope, and so there was not enough time to get a larger sample. Also, future research can expand to post-secondary institutions outside the GTA, to explore the experiences of international students in communities that have fewer minority students and community members. In addition, future research should consider comparing male students and female students in order to examine their differences in experiences between the groups as compared to asking only females. This is especially true in situations where participants might not be exposed to gender as a variable. Lastly, future research focusing specifically on female international students should consider comparing students from top main international student sending countries such as China, India and Nigeria. 
Appendix I. Ryerson Ethics Board Approval Letter

\section{Email sent to applicant on May 31, 2016 09:43:31 AM}

From: rebchair@ryerson.ca

To: m1badmos@ryerson.ca, palbanes@soc.ryerson.ca

Cc: rebchair@ryerson.ca

Subject: REB 2016-161 Status

Date: May 31, 2016 09:43:31 AM

REB 2016-161

Project Title: Is gender important? Transitional services and programming for international students.

Dear Mofiyinfoluwa Badmos,

The Research Ethics Board has completed the review of your submission. Your research project is now approved for a one year period as of May 31, 2017. The approval letter is attached in Adobe Acrobat (PDF) format.

Congratulations and best of luck with the project.

Please note that this approval is for one year only and will expire on May 31, 2017. Shortly before the expiry date a request to complete an annual report will be automatically sent to you. Completion of the annual report takes only a few minutes, enables the collection of information required by federal guidelines and when processed will allow the protocol to remain active for another year.

Please note that REB approval policies require that you adhere strictly to the protocol as last reviewed by the REB. Any modifications must be approved by the Board before they are implemented. Adverse or unexpected events must be reported to the REB as soon as possible with an indication from the Principal Investigator as to how, in the view of the Principal Investigator, these events affect the continuation of the protocol.

Please quote your REB file number (REB 2016-161) on future correspondence.

If you have any questions regarding your submission or the review process, please do not hesitate to get in touch with the Research Ethics Board (contact information below).

No research involving humans shall begin without the prior approval of the Research Ethics Board.

This is part of the permanent record respecting or associated with a research ethics application submitted to Ryerson University. 
NOTE: This email account (rebchair@ryerson.ca) is monitored by multiple individuals. If you wish to contact a specific member of the Research Ethics Board, please do so directly.

Yours sincerely,

Zakiya Atcha, MSW

Research Ethics Co-Ordinator

on behalf of:

Lynn Lavallée, Ph.D.

Chair, Ryerson University Research Ethics Board

(416)979-5000 ext. 4791

lavallee@ryerson.ca

rebchair@ryerson.ca

http://www.ryerson.ca/research

Toni Fletcher, MA

Research Ethics Co-Ordinator

(416)979-5000 ext. 7112

toni.fletcher@ryerson.ca

Zakiya Atcha, MSW

Research Ethics Co-Ordinator

(416)979-5000 ext. 4841

zakiya.atcha@ryerson.ca 
Appendix II. Sample Recruitment Materials (Emails and Twitter)

\section{Participant recruitment for transitional needs for female international students in Toronto study}

Hello

My name is Mofi Badmos, a Master of Arts (MA) candidate in Immigration and Settlement Studies at Ryerson University. I am conducting a research study that explores the transition needs of female international students from Nigeria studying at Post-Secondary institutions in the GTA. I am currently seeking participants that fit the demographic - female, international student, from Nigeria, studying at a post-secondary institution in the GTA. As Canada continues to be a popular destination for International Students, I believe it is important to explore if the current services provided by institutions meet the gender specific needs of female international students from Nigeria.

Participation in this study involves scheduling a meeting with me at a mutually convenient time and place to discuss and answer a series of questions regarding gender specific needs these students. Participation in this study would take approximately 70 minutes of participants' time. I would like to assure you that the study has been reviewed and received ethics clearing through Ryerson Ethics Board. Participation is completely voluntary. The interview will be tape recorded to facilitate analysis, although you can request the tape to be turned off at any time.

I write to also ask for your assistance in sharing this information with students in your association [current students] that fit the demographic and interested participants should please

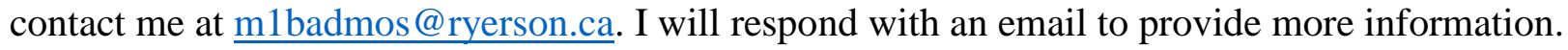

Thank you for your time and assistance.

Sincerely,

Mofi Badmos

\section{Participant recruitment for transitional needs for female international students in Toronto study}

Dear

My name is Mofi Badmos, a Master of Arts (MA) candidate in Immigration and Settlement Studies at Ryerson University. I am conducting a research study that explores the transition needs of female international students from Nigeria studying at post-secondary institutions in the GTA. This research will discuss the needs of this population, explore the current services available and discuss if the needs are being met. As Canada continues to be a popular destination for International Students, I believe it is important to explore if the current 
services provided by institutions meet the gender specific needs of female international students from Nigeria.

As a staff member who has experience assisting international students, I would like to conduct an interview with you, lasting up to 60 minutes. I would like to assure you that the study has been reviewed and received ethics clearing through Ryerson Ethics Board. The interview would be scheduled at a mutually convenient time and place. The interview will be tape recorded to facilitate analysis, although you can request the tape to be turned off at any time.

Please contact me at m1badmos@ryerson.ca if you are willing and available to participate in this study or if you have any questions about the study.

Thank you,

Mofi Badmos

\section{Twitter recruitment:}

Research participants sought \#internationalstudents. Research on transition support for Nigerian females in Toronto. Contact @ MsBadmos 
Appendix III. Sample Interview Questions

\section{Interview questions}

\section{Female students}

\section{Background - Life in Country of Origin}

- What country do you call home? Were born in? What country are you from?

- Can you tell me a little bit about your family?

Probe: siblings? Siblings genders? Oldest/youngest?

- What is life like for a typical young woman in your home country?

o Probes

- Within the family

- in educational institutions

- in society in general

-

\section{Education In Canada}

- Why did you come and study in Canada? Was it an easy decision? Easy process? Other countries considered?

- Probes: Has anyone else in the family gone to study abroad? Come to Canada Is it different being a female child? (especially for those that might have male siblings)

- Why did you choose Canada?

- What do you study here?

- How long to you plan on staying?

- What does academic success mean to you? How do you plan to achieve it here in Canada? What do you feel you need to succeed?

- What is your experience as a female in your home country like in relation to that in Canada when it comes to education?

- What is the thing you like best about your decision to study here? What has been the biggest challenge?

- Who would you say makes up your friend network here in Canada (people from home country?) How did you meet them?

- Do you think life of female students from your country, who are currently living and studying in Canada, is different than male students from your country also living in Canada?

How or why?

\section{Student Services once in Canada}


- Have you used International Student Services at your institution? For what Purposes? (which services?)

- What is your perception of services provided by your institutions?

○ Probe: International student advisors?

- Academic advisors

- Financial aid?

- Events hosted by international student support/centre offices?

- Housing help

- International student orientation

- School counsellors?

- Peer mentoring

- Which do you make use of most often? Do you find it helpful? Which did you find least helpful? Why? How might they be improved?

- Does your financial status play a role in your academic success?

- What services do you access at your institution to help with this?

○ Are you satisfied with them?

○ What else can be done for students in your position?

- What role do you think international student specific services plays in achieving your academic goals? What can be done to serve you better?

- What are your needs for transitioning as female international students?

- Probe: are the challenges unique to being female

- and from West-Africa

- What are your intentions regarding moving back home?

- Probe: do the services play a role?

- Probe: what are some reasons to make you move back?

- If you were an ISA or could create policy to guide ISAs, what would you do?

$\bigcirc$ What services would you enhance?

○ Develop new/differently?

○ Would you eliminate some?

ISAs

- What are some of the services or programming provided by your institution to international students to aid their transition to Canada and Post-secondary education?

$\circ$ Probe: services and programming provided by International student offices specifically and the institution as a whole.

- Based on your experience, what are some challenges specific to female international students? For female students from West-Africa?

$\circ$

- From your experiences, do female students from West Africa come with unique experiences or needs?

$\circ$ What are they?

- what do you see as the biggest challenge they face? 
- Should there be gender specific services and programming for female international students?

○ How would it be beneficial?

- Is gender important in service delivery? Do the current services available take into consideration gender specific needs?

O Why or why not?

- Do transitional services play a role in the retention of international students in Canada? 


\section{References}

Abdulraheem, N. (2011). Rights of women in the pre-colonial and post-colonial era: prospects and challenges. Faculty of Law, University of Ilorin. 1-21

Aderinokun,K. \& Soniyi, T. (2016). Buhari: Nigeria can't afford Forex demand for students studying abroad. This Day Live. Retrieved from http://www.thisdaylive.com/index.php/2016/03/06/buhari-nigeria-cant-afford-forexdemand-for-students-studying-abroad/

Aihie, O. (2009). Prevalence of domestic violence in Nigeria: Implication for counselling. Edo Journal of Counselling, 2(1), 1-8

Aja-Okorie, U. (2013). Women education in Nigeria: Problems and implications for family role and stability, European Scientific Journal, 9(28), 272-282

Alboim, N. (2009). Adjusting the Balance: Fixing Canada's Economic Immigration Policies. Toronto: Maytree Foundation

Allanana, M. (2013). Patriarchy and gender inequality in Nigeria: the way forward. European Scientific Journal, 9(17), 115-146

At a glance: Nigeria. (n.d.). Retrieved July 24, 2016, from http://www.unicef.org/infobycountry/nigeria_statistics.html

Bonazzo, C. \& Wong, Y.J. (2007). Japanese international female students' experience of discrimination, prejudice, and stereotypes, College Student Journal, 41(3), 631-639

CBIE (2015). Facts and figures. Retrieved April 19, 2016 from http://www.cbie.ca/aboutie/facts-and-figures/

CBIE Research (2015). The integration challenge: connecting international students with their Canadian peers. Canadian Bureau for International Education. Retrieved from http://cbie.ca/wp-content/uploads/2016/04/CBIE-Research-in-Brief-2-The-IntegrationChallenge-EN.pdf

Chira, S. (2011). International Students in Atlantic Canada: Investments and Returns. Canadian Diversity, 8(5), 30-35

Cox, C. (2012). International students in Canada: Policies and practices for social inclusion (Unpublished Major Research Paper). Ryerson University, Toronto.

Creswell, J.W. (2013). Qualitative Inquiry \& Research Design: Choosing from five 
approaches. $3^{\text {rd }}$ Edition. Los Angeles: Sage.

Deem, R. (2003). Gender, organizational cultures and the practices of manager-academics in UK universities. Gender, Work and Organization, 10(2), 239-260

Determine your eligibility - Study in Canada. (n.d.). Retrieved July 24, 2016, from http://www.cic.gc.ca/english/study/study-who.asp

Edwards-Joseph, A. \& Baker, S. (2014). Factors Caribbean overseas students perceive influence their academic self-efficacy. Journal of International Students, 4(1), 48-59

Esere,M., Idowu,A., \& Omotosho, J. (2009). Gender-based domestic violence against children: experiences of girl children in Nigeria. Journal of Psychology in Africa, 19(1), 107-112

Facts and figures 2011 - Immigration overview: Permanent and temporary residents. (n.d.).

Retrieved July 24, 2016, from

http://www.cic.gc.ca/english/resources/statistics/facts2011/temporary/13.asp

Faid-Douglas, R. (2000). International female students' academic success: A phenomenological study (Unpublished Dissertation). University of Nebraska, Nebraska.

Gates-Gasse, E. (2010). “Two step” Immigration: Canada’s new immigration system raises troubling issues. Retrieved April 20, 2016 from https://www.policyalternatives.ca/publications/monitor/two-step-immigration

Govt. Canada. (2014). Canada’s International Education Strategy. Retrieved April 19, 2016 from http://international.gc.ca/global-markets-marches-mondiaux/assets/pdfs/overviewapercu-eng.pdf

Hwang, B., Bennett, R. \& Beauchemin, J. (2014). International students' utilization of counseling services. College Student Journal, 48(3), 347-355

Iliyasu, Z., Abubakar, I., Aliyu, M., Galadanci, H., \& Salihi, H. (2011). Prevalence and correlates of gender-based violence among female university students in Northern Nigeria. African Journal of Reproductive Health, 15(2), 111-9

Kamara, A. \& Gambold, L. (2011). Immigration and diversity: Exploring the challenges facing international students on and off campus. Canadian Diversity, 8(5), 25-30

Knight, J. (2004). Internationalization remodeled: definition, approaches, and rationales. Journal of Studies in International Education, 8(1), 5-31

Lowe, S. (2011). Welcome to Canada? Immigration incentives may not be enough for international students to stay, Canadian Diversity, 8(5), 20-24 
Mesidor, J. \& Sly, K. (2016). Factors that contribute to the adjustment of international students. Journal of International Students, 6(1), 262-282

Mohanty, C (1988). Under Western Eyes: Feminist scholarship and colonial discourses. Feminist Review, 30(1), 1-27

Mishra, R (2013). Postcolonial feminism: Looking into within-beyond-to difference. International Journal of English and Literature, 4(4), 129-134

Nwanesi, P. (2006). Development, micro-credit and women's empowerment: a case study of market and rural women in Southern Nigeria (Unpublished Dissertation). University of Canterbury, New Zealand.

Oniye, A. (2013). Women education: problems and implications for family responsibility. The Nigerian Journal of Guidance and Counselling, 9(1), 1-12

Park, H. (2010). The stranger that is welcomed: female foreign students from Asia, the English language industry, and the ambivalence of 'Asia rising' in British Columbia, Canada. Gender, Place and Culture, 17(3), 337-355

Pidgeon, M. \& Andres, L. (2005). Demands, challenges, and rewards: The first year experiences of international and domestic students at Four Canadian universities. Department of Educational Studies, UBC

Popadiuk, N. (2008). Intimate relationships of female international students. Multicultural counseling and development, 36, 206-218

Regina, A. (2003). Welcome to Canada? Experiences and views of international graduate students at the University of British Columbia (Unpublished Thesis). University of British Columbia, British Columbia

Roach, E. (2011). Service needs and gaps for international students transitioning to permanent residency in a "two-step" immigration process: A Toronto based study (Unpublished Major Research Paper). Ryerson University, Toronto

Schwarz, H., \& Ray, S. (2005). A companion to postcolonial studies. Malden, MA: Blackwell.

Sinacore, A. \& Lerner, S. (2013). The cultural and educational transitioning of first generation immigrant undergraduate students in Quebec, Canada. International Journal for Educational and Vocational Guidance, 13, 67-85

Stay in Canada after graduation. (n.d.). Retrieved July 24, 2016, from http://www.cic.gc.ca/english/study/work-postgrad.asp 
Tyagi, R. (2014). Understanding Postcolonial Feminism in relation with Postcolonial and Feminist theories. International Journal of Language and Linguistics, 1(2), 46-50

Zhai, L. (2002). Studying international students: adjustment issues and social support. ERIC Institute of Education Sciences, 1-20 